\title{
The Hydrologic Cycle of the La Plata Basin in the WCRP-CMIP3 Multimodel Dataset
}

\author{
RAMIRO I. SAURRAL \\ Department of Atmospheric and Oceanic Sciences (FCEN-UBA), and Center for Atmospheric and \\ Oceanic Research (CONICET-UBA), Buenos Aires, Argentina
}

(Manuscript received 20 May 2009, in final form 1 April 2010)

\begin{abstract}
General circulation models (GCMs) forced under different greenhouse gases emission and socioeconomic scenarios are currently the most extended tool throughout the scientific community that is used to infer the future climate on Earth. However, these models still have problems in capturing several aspects of regional climate variability in many parts of the globe. In this paper, the hydrological cycle of the La Plata Basin is simulated using the variable infiltration capacity (VIC) distributed hydrology model and forced with atmospheric data from different GCMs to determine to what extent errors in temperature and precipitation fields impact the hydrology of the basin. The skill assessment is performed in terms of simulated runoff at different closing points. Simulated hydrographs show that all of the GCMs present deficiencies in simulating the regional climatology of southern South America, and this leads to a very poor representation of the hydrological cycle of the main rivers across the basin. Two unbiasing schemes are then proposed as a means of correcting the GCM outputs before forcing the hydrology model, and comparisons between biased and unbiased simulations are also performed. Results indicate that both schemes, though methodologically different, reduce the water cycle simulation bias. Finally, VIC is forced with bias-corrected data from the GCMs for future decades (2030 and 2070) under different socioeconomic scenarios [e.g., the Intergovernmental Panel on Climate Change's (IPCC) Special Report on Emissions Scenarios (SRES) scenarios A1B, A2, and B1] to determine the potential changes in streamflow due to climate change for the rest of the present century.
\end{abstract}

\section{Introduction}

Human dependence on rivers is particularly remarkable in South America, where two of the five largest river basins in the world (the Amazon and La Plata, first and fifth largest, respectively) are located. The La Plata Basin (LPB) covers an area of more than 3 million $\mathrm{km}^{2}$ and includes parts of southern and eastern Brazil, Paraguay, eastern Bolivia, and much of Uruguay and central and northern Argentina (Fig. 1). The three main rivers in the basin are the Paraná, the Paraguay, and the Uruguay [for a detailed description of the basin hydrology see Berbery and Barros (2002)]. The basin is highly dependent on climate, with a strong precipitation signal related to ENSO (Grimm et al. 2000; Berri et al. 2002; Grimm and Tedeschi 2009; Camilloni and Barros 2000) and periods of excessive

Corresponding author address: Ramiro I. Saurral, Dept. of Atmospheric and Oceanic Sciences, University of Buenos Aires, Int. Guiraldes 2160, Ciudad Universitaria, Pab. 2 (C1428EGA), Buenos Aires, Argentina.

E-mail: saurral@cima.fcen.uba.ar precipitation that lead to extensive floods (Camilloni and Barros 2003; Camilloni 2005) alternating with long-lasting dry spells (Penalba and Vargas 2008; Doyle et al. 2008). Significant changes in temperature and precipitation were registered during recent decades across the basin (García and Vargas 1998; Barros et al. 2000), and these changes were in part responsible for the observed trends in the streamflows. Other effects, such as land use change, were also shown to have an impact on the hydrology of the basin (Saurral et al. 2008).

As hundreds of millions of people across southeastern South America depend upon the hydrology of this basin, and within the context of a changing climate, it is of interest to infer the possible impacts of future temperature and precipitation conditions on the streamflow of these rivers. The World Climate Research Programme's (WCRP) phase 3 Coupled Model Intercomparison Project (CMIP3) multimodel dataset provides a comprehensive set of general circulation models (GCMs) simulations of the nearpast, present, and future climate (generally covering the period 1860-2100), and these outputs are a potentially useful tool for performing these inferences. Many previous 


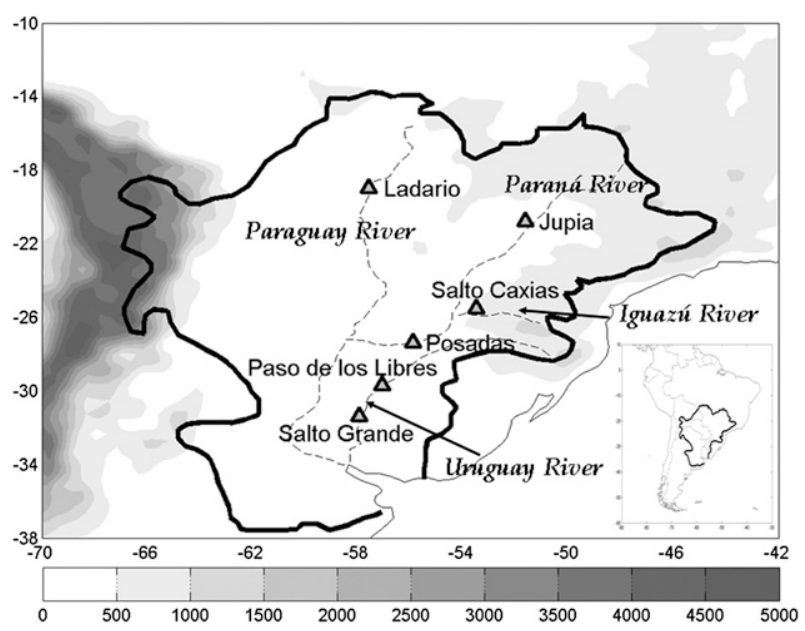

FIG. 1. The location of LPB in South America. The four rivers considered in this analysis (Paraná, Paraguay, Uruguay, and Iguazú) are shown with dashed lines. Triangles mark the locations of the closing points: Ladario in the Paraguay River, Jupiá and Posadas in the Paraná River, Salto Caxias in the Iguazú River, and Paso de los Libres and Salto Grande in the Uruguay River. The topography of the basin is shaded. Topography units are in meters.

studies have analyzed in detail the skill of some of these models in representing the present climate (Dai 2006; Perkins et al. 2007; Raphael and Holland 2006). Very recently, Vera and Silvestri (2009) analyzed the skill of seven of these models to represent the interannual variability of precipitation over South America and showed that the models have problems in representing the warm season precipitation maximum over southeastern South America as related to the South Atlantic convergence zone (SACZ; Nogués-Paegle and Mo 1997) and the cold season rainfall maximum located in northeastern Argentina, Uruguay, and southern Brazil.

During the past several decades, the hydrological community has dedicated much of its efforts toward improving our understanding and prediction of river streamflow variability by means of case study analysis methods (Pielke and Downton 2000; Mo et al. 1997; Laing 2004) or by simulating river streamflows using more complex tools like hydrological models (Su and Lettenmaier 2009; Seguí et al. 2009; Mattheussen et al. 2000; Saurral et al. 2008; Collischonn et al. 2005). In the case of river streamflow prediction using GCMs, Wood et al. (2002) forced a distributed hydrology model with monthly forecasts of temperature and precipitation from the National Centers for Environmental Prediction/Climate Prediction Center (NCEP/CPC) Global Spectral Model and showed the need for bias correction in both temperature and precipitation forecasts before using the data as a forcing to the hydrology model, as GCMs tend to commonly have large biases in both variables.
In this paper, the impacts of the GCMs' misrepresentations in precipitation and temperature on the hydrological cycle of the LPB are determined by forcing a hydrological model with observed precipitation and temperature data from the period 1990-99 and also using input data from five different GCMs for the same time period. Results show that the GCMs are unable to capture the main climate features across the LPB, leading to poor hydrological cycle assessments and thus, unbiasing the meteorological fields before forcing the hydrological model becomes crucial. Two unbiasing schemes are then applied on both the temperature and precipitation fields, and the improvements in the water cycle simulations are quantified. For inferring the potential behavior of streamflows in the upcoming decades, simulations were also performed forcing the VIC model with GCM data for two future decades (2030-39 and 2070-79) and for three different socioeconomic/emission scenarios: the Intergovernmental Panel on Climate Change's (IPCC) Special Report on Emissions Scenarios (SRES) scenarios A1B, A2, and B1.

The paper is organized as follows: section 2 describes the datasets and the VIC simulations and unbiasing methodologies used in this research; section 3 describes the temperature and precipitation climatology of the LPB and shows the comparison between the observations and the GCMs datasets. In section 4 the VIC model's performance on the LPB using observed meteorological forcings is analyzed; the comparison between the hydrological cycles simulated using biased and unbiased GCMs outputs is shown in section 5. Section 6 contains results from the simulations of future streamflows as obtained under different socioeconomic scenarios for the upcoming decades. Section 7 presents a discussion of the results and the conclusions.

\section{Data and methodology}

\section{a. The VIC distributed hydrology model}

The VIC model (Liang et al. 1994, 1996; Nijssen et al. 1997) is a distributed grid-based land surface scheme that solves both water and energy balances on a grid mesh. It uses a mosaic-like representation of land cover and a subgrid parameterization for infiltration and it requires information on soil texture, topography, and vegetation. Soil data were derived from the 5-min Global Soil Data Task dataset from the Distributed Active Archive Center (2000), and vegetation information was obtained from the University of Maryland's 1-km Global Land Cover product (Hansen et al. 2000). The model is forced with atmospheric data that can be determined by the user (depending on its availability). In this paper, VIC was forced using daily minimum and maximum temperature 


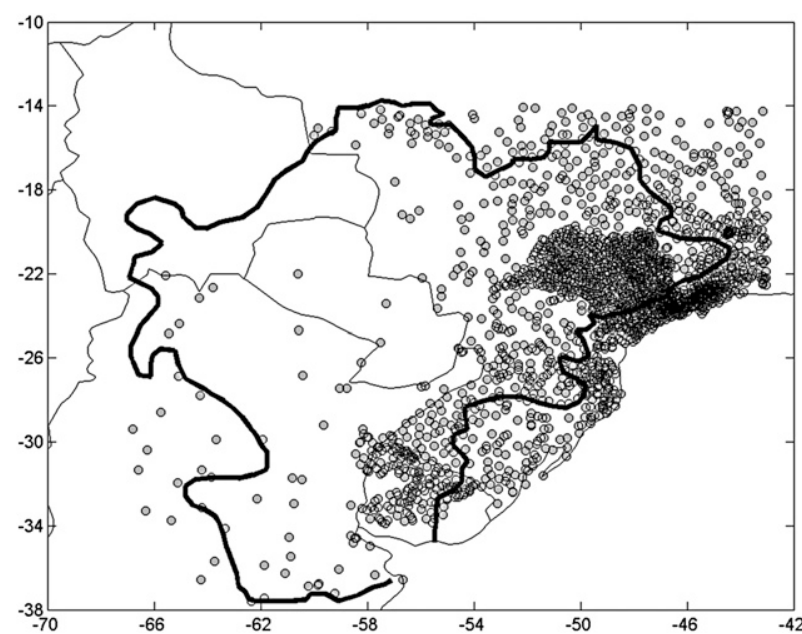

FIG. 2. Spatial distribution of the precipitation gauge stations across LPB during the period 1973-99 (circles).

and daily precipitation data covering the period 1990-99 over the entire LPB domain and with a horizontal resolution of $0.125^{\circ}$ in both latitude and longitude, leading to a total of 18641 grid points. Calibration was done using methods described in Su et al. (2005). Temperature and precipitation data were obtained from the National Climate Data Center (NCDC) Global Daily Climatology Network (GDCN) and CPC stations. Precipitation information was also enriched using more gauge stations provided by the National Weather Service of Argentina, the National Meteorological Direction of Uruguay, and the Brazilian National Water Agency. Figures 2 and 3 display the locations of the precipitation stations and the minimum and maximum temperature stations, respectively. In general, the spatial distribution of the precipitation stations is good in the eastern part of the basin (across the Uruguay and upper and middle Paraná basins) but it is quite poor over the western part (in particular over the Paraguay basin). Temperatures stations, on the other hand, display a more homogeneous distribution. All the atmospheric data were gridded into regular $0.125^{\circ} \times 0.125^{\circ}$ grid meshes before running VIC. The gridding of the temperature and precipitation data was performed using the kriging method. The model outputs are the daily, monthly, and annual mean evapotranspiration and surface and subsurface runoff at each of the 18641 grid points, and the routing scheme developed in Lohmann et al. $(1996,1998)$ was applied to the VIC outputs to integrate the streamflow over the different LPB subbasins and to obtain discharges at selected closing points.

\section{b. GCMs}

Five GCMs were considered in this paper: the Centre National de Recherches Météorologiques Coupled

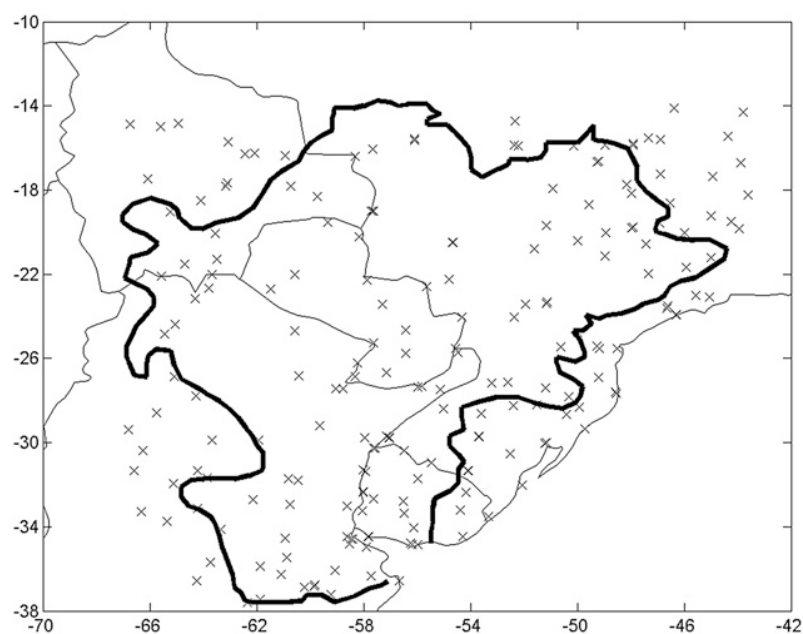

FIG. 3. Spatial distribution of temperature stations across LPB during the period 1973-99 (triangles).

Global Climate Model, version 3 (CNRM-CM3; SalasMeliá et al. 2005); the ECHAM5/Max Planck Institute Ocean Model (MPI-OM; Roeckner et al. 2006); the Geophysical Fluid Dynamics Laboratory Climate Model version 2.0 (GFDL CM2.0; Delworth et al. 2006); the Canadian Centre for Climate Modelling and Analysis (CCCma) Coupled General Circulation Model, version 3.1 (CCCma/CGCM3-T47; Flato 2009); and the Goddard Institute for Space Studies Atmosphere-Ocean Model (GISS-AOM; Russell 2009). The levels of horizontal resolution vary among the models, from $3.75^{\circ} \times 3.75^{\circ}$ in $\mathrm{CCCma} / \mathrm{CGCM} 3-\mathrm{T} 47$ to $2.8^{\circ} \times 2.8^{\circ}$ in $\mathrm{CNRM}-\mathrm{CM} 3$ and $3.0^{\circ}$ (latitude) $\times 4.0^{\circ}$ (longitude) in GISS-AOM, and from $2.0^{\circ}$ (latitude) $\times 2.5^{\circ}$ (longitude) in GFDL CM2.0 to $1.88^{\circ} \times 1.88^{\circ}$ in ECHAM5/MPI-OM (in the interest of brevity, hereafter CNRM-CM3, GFDL-CM2.0, ECHAM5/ MPI-OM, CCCMA/CGCM3-T47, and GISS-AOM will be referred as CNRM, GFDL2.0, ECHAM5, CGCM, and GISS, respectively). Atmospheric data from the models are the same as those from the observations (daily minimum and maximum temperature and daily precipitation) covering the same region and same time period (1990-99) and were obtained from the CMIP3 multimodel dataset, which is available from the Program for Climate Model Diagnosis and Intercomparison Web site (PCMDI; http:// www-pcmdi.llnl.gov/ipcc/about_ipcc.php). The data were also gridded into a $0.125^{\circ} \times 0.125^{\circ}$ grid mesh following the same interpolation method as with the observations.

The inferences on future climate made with the CMIP3 GCMs were driven by forcing the models with different socioeconomic scenarios related to the future behavior of (mainly) the worldwide economy and population. These scenarios can be divided into four groups: A1, A2, B1, and $\mathrm{B} 2$. The A1 scenario is characterized by a slow 
increase in global population (reaching 9 billion inhabitants by 2050) and a rapid economic increase, accompanied by the development of new and more efficient technologies. This group is divided in terms of the technological development it is based on: with emphasis on fossil fuels (A1FI), with emphasis on nonfossil fuels (A1T), and a balance between the different energy sources (A1B). The A2 scenario considers a rapid population increase along with regionally oriented economic development; the B1 scenario, on the other hand, supposes a more ecologically friendly world, with the introduction of cleaner and more efficient technologies. Finally, scenario B2 is characterized by slow demographic growth and clean technologies. This means that those scenarios starting with $\mathrm{A}$ are related to a bigger increase in greenhouse gases than those starting with B. For further details on this issue the reader is referred to the last Intergovernmental Panel on Climate Change report (Solomon et al. 2007).

\section{c. Streamflow prediction assessment}

The performance of VIC forced with observations (model skill assessment) and with the GCMs to represent the hydrological cycle of the three main rivers in LPB was analyzed at six different closing points: Salto Grande and Paso de los Libres in the Uruguay River, Jupiá and Posadas in the Paraná River, Ladario in the Paraguay River, and Salto Caxias in the Iguazú River (which is a tributary of the Paraná River). Station locations are displayed in Fig. 1. Previous studies have shown the ability of this distributed model to represent the hydrological cycle of the Uruguay River (Saurral et al. 2008) as well as of the other rivers of the basin ( $\mathrm{Su}$ et al. 2008; $\mathrm{Su}$ and Lettenmaier 2009). The skill of VIC in simulating the hydrological cycle of LPB (and also for the simulations using biased and unbiased GCMs data) was assessed by calculating the square of the correlation coefficient $\left(R^{2}\right)$, the bias, and the Nash-Sutcliffe coefficient of the efficiency (NSE). These statistical parameters are defined as follows:

$$
R^{2}=\frac{\sum_{i=1}^{n}\left(Q_{i}^{\mathrm{SIM}}-\overline{Q^{\mathrm{SIM}}}\right)\left(Q_{i}^{\mathrm{OBS}}-\overline{Q^{\mathrm{OBS}}}\right)}{\frac{1}{(n-1)} \sqrt{\sum_{i=1}^{n}\left(Q_{i}^{\mathrm{SIM}}-\overline{Q^{\mathrm{SIM}}}\right)^{2}} \sqrt{\sum_{i=1}^{n}\left(Q_{i}^{\mathrm{OBS}}-\overline{Q^{\mathrm{OBS}}}\right)^{2}}}
$$

$$
\operatorname{Bias}=\frac{\sum_{i=1}^{n}\left(Q_{i}^{\mathrm{SIM}}-Q_{i}^{\mathrm{OBS}}\right)}{\sum_{i=1}^{n} Q_{i}^{\mathrm{OBS}}} \times 100 \%, \quad \text { and }
$$

$$
\mathrm{NSE}=1-\left[\frac{\sum_{i=1}^{n}\left(Q_{i}^{\mathrm{SIM}}-Q_{i}^{\mathrm{OBS}}\right)^{2}}{\sum_{i=1}^{n}\left(Q_{i}^{\mathrm{OBS}}-\overline{Q^{\mathrm{OBS}}}\right)^{2}}\right],
$$

where $Q^{\mathrm{OBS}}$ represents the observed streamflow at the selected closing points and $Q^{\mathrm{SIM}}$ represents that simulated with VIC. The performance assessment was done only at the monthly time scale because, although VIC also produces daily streamflow outputs, the purpose of this paper is to determine the accuracy of VIC in capturing the hydrological cycle of the basin. After assessing VIC performance on LPB forced with the observations, the hydrological model was forced with biased and unbiased GCM data. The same statistical parameters were also computed to determine the capability of the climate models in representing the water cycle of the basin before and after unbiasing, but the comparisons were performed between the mean GCM-simulated streamflows and the mean streamflow simulated with the observations.

\section{d. GCMs unbiasing schemes}

GCMs have severe deficiencies in simulating the climatology of southern South America, particularly with regard to precipitation (see our results in section 3). For this reason, assessing future variations of the hydrological cycle for the upcoming decades using these models requires the application of corrective (unbiasing) schemes. These corrections are useful, given that they are a good tool for interpreting the GCM outputs relative to their own climatology rather than the observed climatology (Wood et al. 2002). Correcting GCM data can be performed by means of dynamical downscaling, commonly consisting of nesting a regional model to a GCM over the area of interest as a way of increasing the horizontalvertical resolution of the atmospheric simulations and, thus, improving its representation of the circulation, or by statistical downscaling, in which statistical parameters (distribution momentums, percentiles) are calculated and used to correct the GCM outputs. The two approaches in this paper belong to the later category.

Two unbiasing schemes for temperature and precipitation were applied to the GCM data before and after running VIC, and comparisons of the results were then performed. As unbiasing computation and validation requires two independent time periods (one to compute the unbiasing variables and the other to which the unbiasing scheme is applied, as a way of demonstrating the efficiency of the method), monthly mean temperature and precipitation data for the observations and for each of the GCMs were also available for the period 1973-89 (17 yr), so this period was used for computing the unbiasing variables 
and the period 1990-99 was used for comparison of the biased and unbiased datasets and their ability to simulate the water cycle of the basin. The first scheme requires computing the differences in the long-term (1973-89) monthly means of temperature and precipitation between the observations and each of the GCMs. These differences are then used to correct the daily 1990-99 GCM data, so that the original (1990-99) daily temperatures are added the difference between the observed (1973-89) and the GCM means and the original daily precipitation data are multiplied by the quotient between the observed (197389) and the GCM means, at each of the 18641 grid cells. This scheme then removes the systematic GCM bias in both fields in a monthly time step. The second unbiasing scheme is based on the percentile distribution of both temperature and precipitation data for the observations and the GCMs and is similar to the unbiasing method used in Wood et al. (2002). The scheme requires computing the monthly (January-December) percentiles of temperature and precipitation (for the observations and the five GCMs) during the period 1973-89. Then, the daily 1990-99 data are corrected by computing the monthly values of the mean temperature and accumulated precipitation (for each of the 120 months between January 1990 and December 1999) for each GCM and determining the corresponding percentile of the distribution. The same percentile but now in the observations is then found and the correction is performed, in the case of temperature, by adding to each daily data point the difference between the value corresponding to that percentile in the observations and that in the GCM distribution. In the case of precipitation, the GCM data are corrected by multiplying each daily data point by the quotient between the corresponding percentile in the observations and the percentile in the GCM. The same procedure is performed for each of the 120 months, for each of the 18641 grid cells, and each of the five GCMs. The differences in the VIC outputs before and after the application of the unbiasing scheme on temperature and precipitation are then quantified and discussed.

\section{e. Future climate scenarios}

In this paper, three socioeconomic scenarios (A1B, A2, and B1) and two future decades (2030-39 and 207079) were considered to force VIC and obtain potential future water availability scenarios for LPB. Monthly mean temperatures and accumulated precipitation totals were available from the five GCMs for the three scenarios and for the 120 months of each of the two decades, except for information from the B1 scenario for the GISS model, which was not available. These monthly data were taken into the spatial and temporal scales of the VIC model inputs. This was performed following the method suggested in Wood et al. (2002), in which for each month and for each GCM, 1 yr from the period 1990-99 was randomly chosen and for each VIC cell the observed daily values of the temperature and precipitation were scaled so that the precipitation total for that month equaled the monthly amount for that GCM and that future period, and temperatures (both daily minimum and maximum) were scaled so that their average reproduced the forecast mean temperature for the corresponding GCM and month.

\section{Temperature and precipitation climatology}

LPB lies in a subtropical climate region, with warm summers and mild winters. Temperatures in the central and northern parts of the basin usually reach values in excess of $40^{\circ} \mathrm{C}$ in the warm season, while winters are cold only in the south, where frequent frosts take place. Annual mean temperatures are highest in northern Paraguay and eastern Bolivia. In terms of precipitation, there are two distinguishable maximums: one in the far northern part of the basin, which is mainly related to summer monsoonal activity (Vera et al. 2006), and another one over the upper Uruguay River basin (UUR), in northeastern Argentina and southern Brazil, where precipitation occurs throughout the year.

Figure 4 shows the annual mean temperature derived from the observations in the period 1973-89 and the difference between each GCM's mean temperature and the observations. The highest annual mean temperatures throughout the basin are located in the northern part, an area covering southeastern Bolivia, western Paraguay, and south-central Brazil with more than $24^{\circ} \mathrm{C}$. At the western edge of the basin, the topography increases sharply (see Fig. 1) and the mean temperature displays a minimum. GCMs in general tend to represent quite well the spatial variability and the magnitude of temperature across the basin, although ECHAM5 and GISS tend to be warmer (with differences ranging from $2^{\circ}$ to $5^{\circ} \mathrm{C}$ ) over central Argentina. All the models are colder than the observations in the eastern part of the basin, near the UUR area, with differences exceeding $4^{\circ} \mathrm{C}$ in ECHAM5. It is interesting to note that despite the relatively low resolutions of the GCMs, all of them are able to capture decently the low temperatures associated with the Andes Cordillera. However, this low resolution is responsible for the Andes being wider and lower in the GCMs than they really are and, thus, for the lower temperatures to the east of the mountains near the western edge of the basin in the five GCMs.

In terms of annual precipitation (Fig. 5), the differences are more important. The climatology derived from the 1973-89 observations (Fig. 5a) displays a rainfall maximum 
a) OBS - 1973-1989

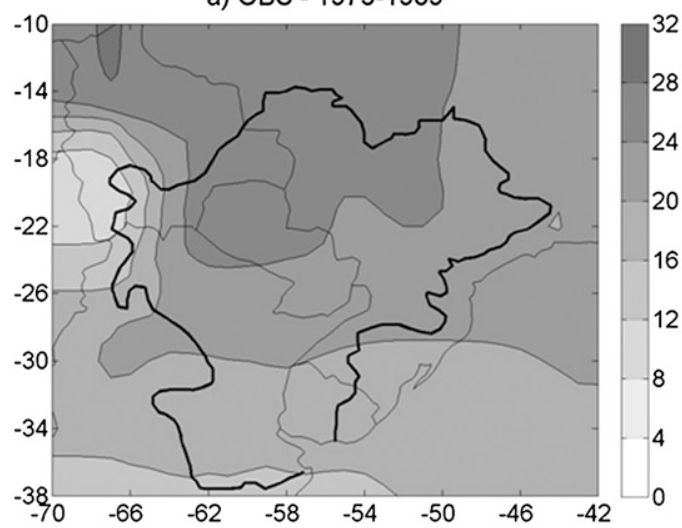

c) ECHAM - 1973-1989

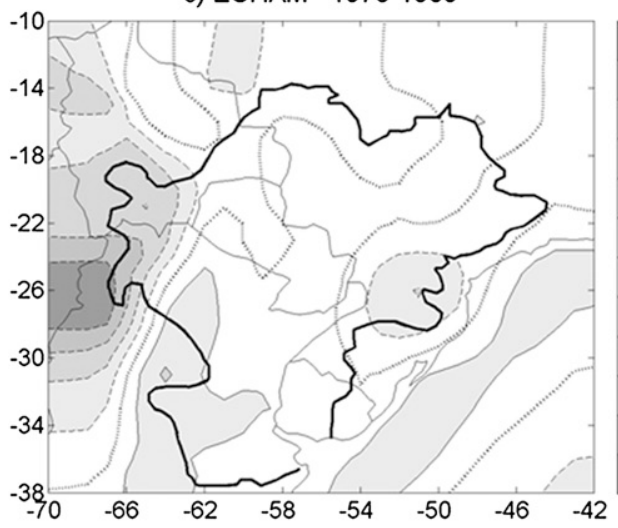

e) CGCM - 1973-1989

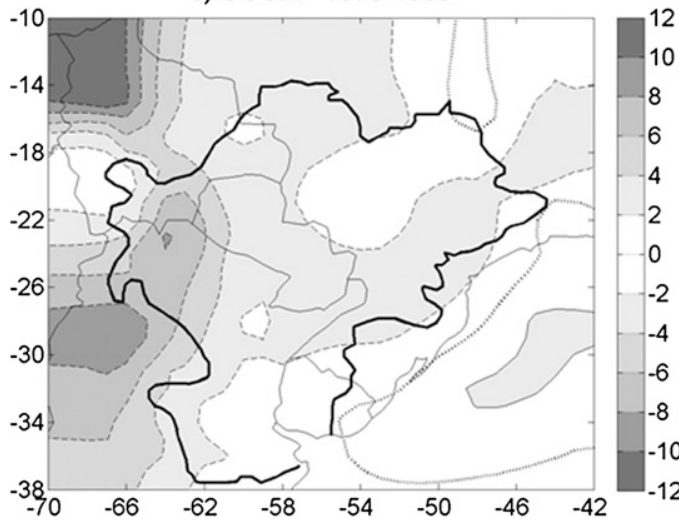

b) CNRM - 1973-1989

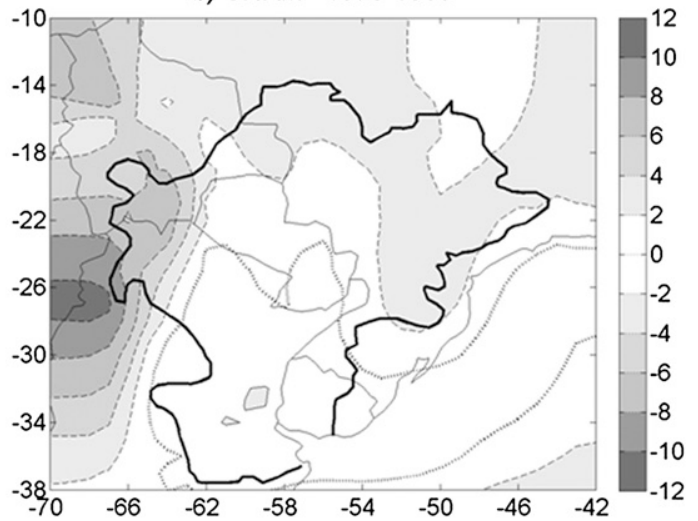

d) GFDL - 1973-1989
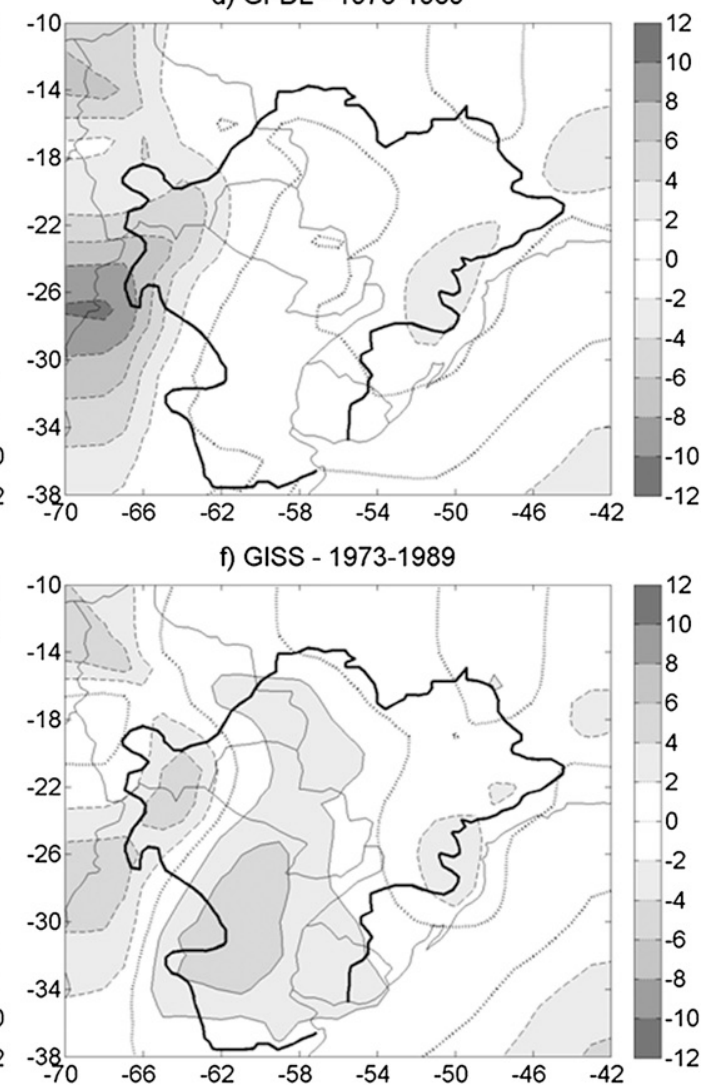

FIG. 4. (a) Annual mean temperature $\left({ }^{\circ} \mathrm{C}\right)$ in the observations during the period $1973-89$ and the differences among the (b) CNRM, (c) ECHAM5, (d) GFDL2.0, (e) CGCM, and (f) GISS means with respect to the observed mean. Negative differences (observations warmer than the GCM) are displayed as contours circled with dashed lines, and positive differences are shown with solid lines. The zero contour is indicated with a dotted line.

to the north of the basin, mainly over central Brazil from roughly $15^{\circ} \mathrm{S}$ northward, related to summer convective activity that characterizes the South American monsoon (Vera et al. 2006), and is almost totally explained by rainfall occurring in the December-February (warm) season (Fig. 6a), when rainfall rates are about $10 \mathrm{~mm}_{\text {day }}{ }^{-1}$. The other maximum occurring in southern Brazil is also visible. Precipitation there occurs all year long but has a maximum in winter, mainly due to transient/baroclinic activity (Vera et al. 2002), with rainfall rates exceeding $5 \mathrm{~mm}$ day $^{-1}$ (Fig. 7a). The western part of the basin is dry, with annual amounts of less than $750 \mathrm{~mm}$ over west-central Argentina. The GCMs, however, display several differences with respect to the observations. CNRM (Fig. 5b) simulates rainier conditions over the northern half of the basin, with excesses of between 300 and $900 \mathrm{~mm}_{\text {year }}{ }^{-1}$, 
a) OBS - 1973-1989

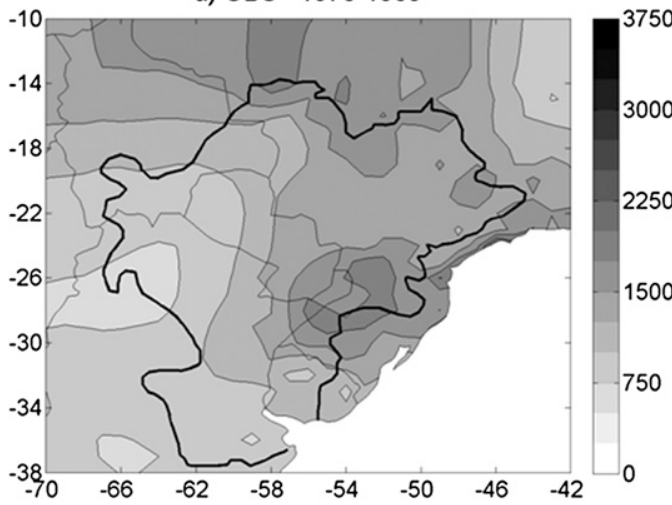

c) ECHAM - 1973-1989
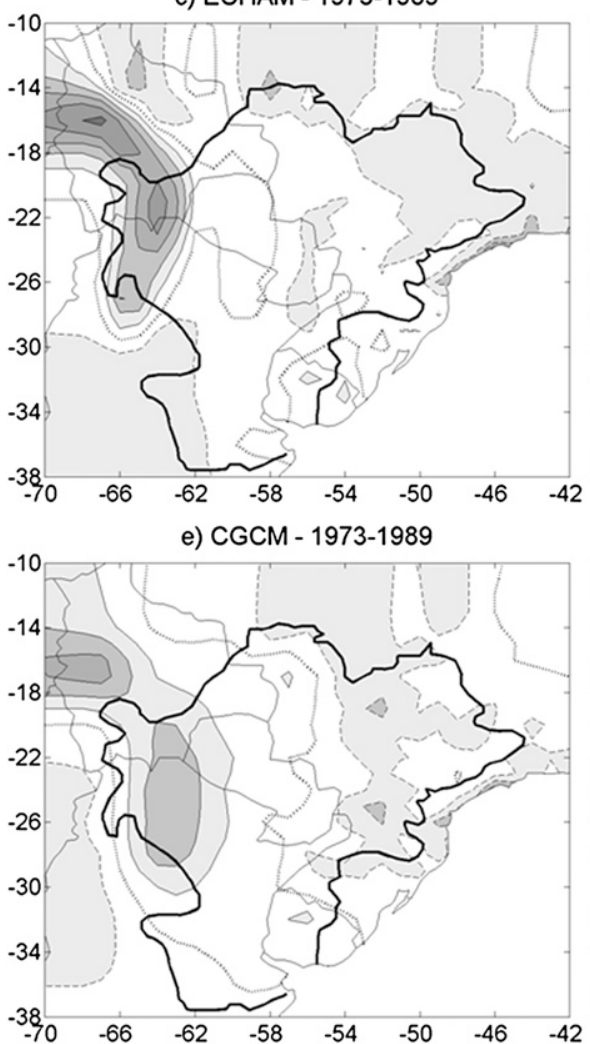

b) CNRM - 1973-1989

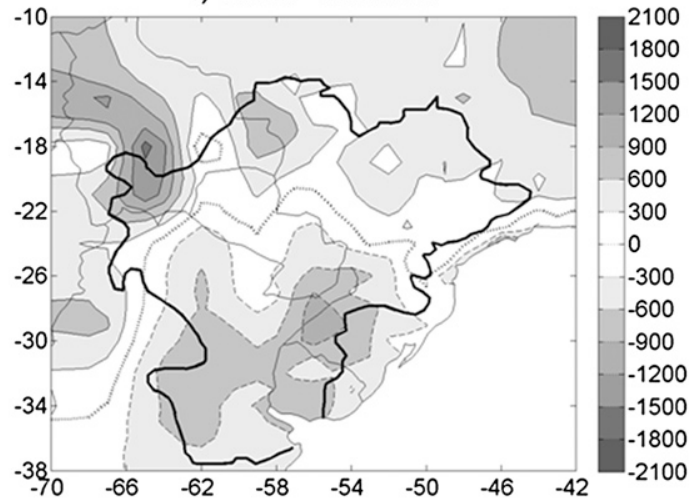

d) GFDL - 1973-1989
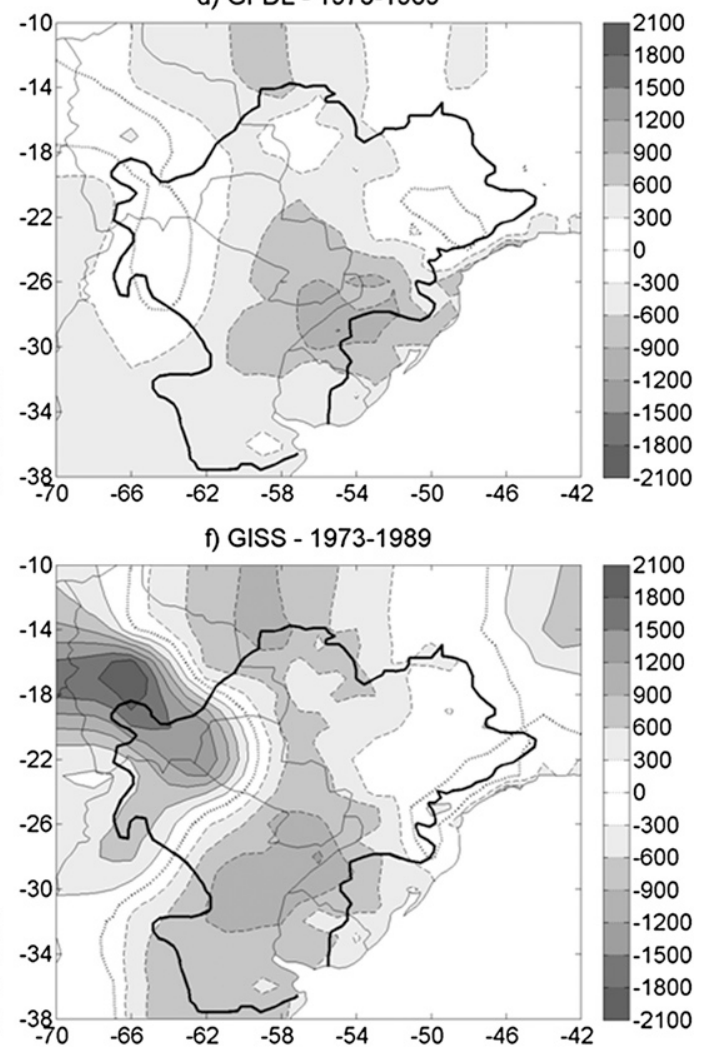

FIG. 5. (a) Annual mean accumulated precipitation $\left(\mathrm{mm} \mathrm{yr}^{-1}\right)$ in the observations during the period $1973-89$ and the differences among the (b) CNRM, (c) ECHAM5, (d) GFDL2.0, (e) CGCM, and (f) GISS means with respect to the observed mean. Negative differences (observations rainier than the GCM) are displayed as contours circled with dashed lines, and positive differences are shown with solid lines.

and much drier conditions over the central and southern parts of LPB. In fact, over southern Brazil this model represents about $1000 \mathrm{~mm}$ (50\% the annual mean) less rainfall than actually falls. This is explained by its poor representation of the winter maximum there (Fig. 7b), with rates of only $1-2 \mathrm{~mm}$ day $^{-1}$. Annual precipitation over the Andes Cordillera is overestimated in this model, but comparisons should be made carefully given that precipitation stations are very scarce in that area (Fig. 2).
GFDL2.0 and GISS are rather similar to CNRM in terms of annual mean precipitation, with underestimations of about 1000-1200 mm over the Uruguay River basin (Figs. 5d and 5f). This is explained in part by the drier conditions simulated by both models in the warm season (Figs. 6d and 6f) and also during the winter (Figs. 7d and 7f), when simulated rainfall is less than $1 \mathrm{~mm} \mathrm{day}^{-1}$ in GFDL2.0 and does not exceed $3 \mathrm{~mm}$ day $^{-1}$ in GISS. GFDL2.0 does not underestimate the annual precipitation 
a) OBS - 1973-1989
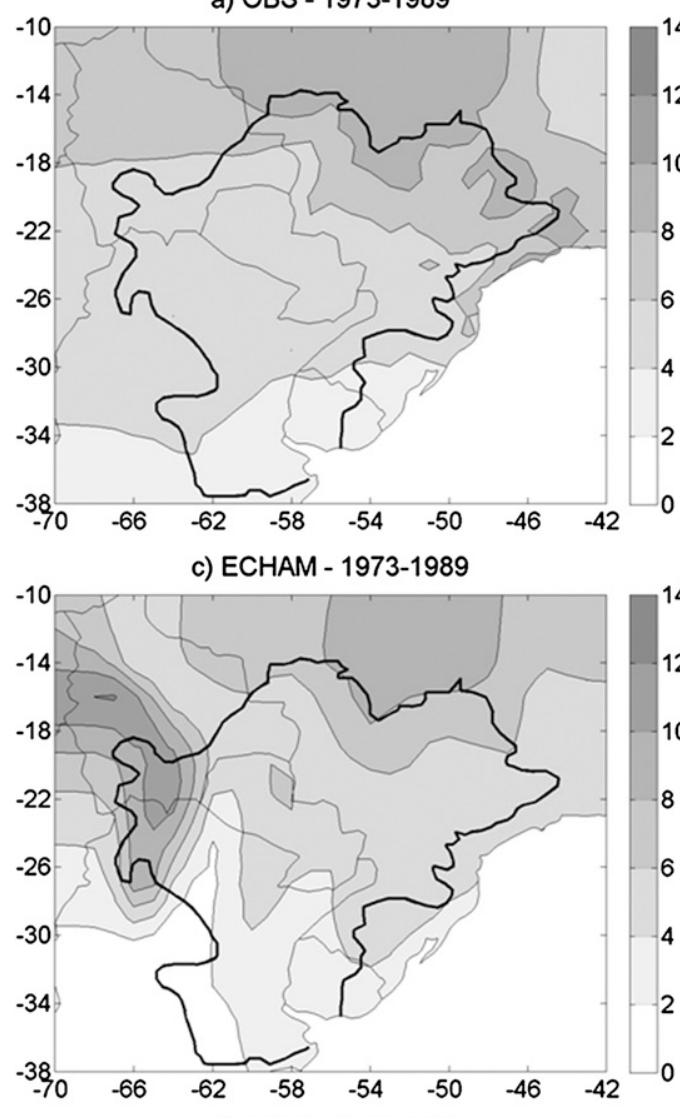

e) CGCM - 1973-1989

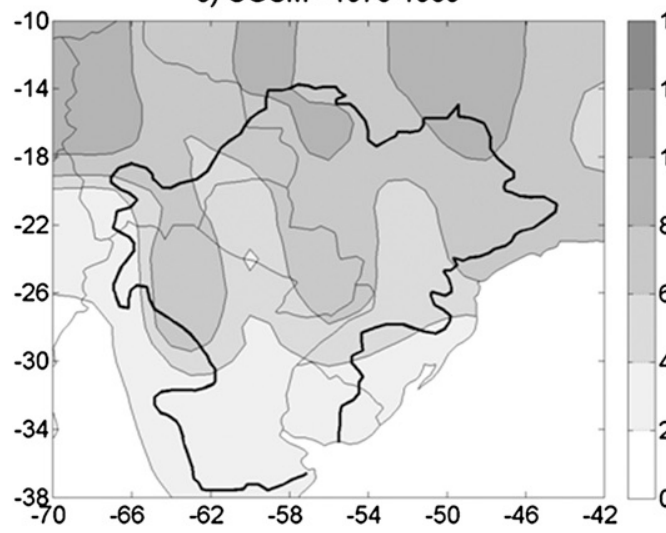

b) CNRM - 1973-1989

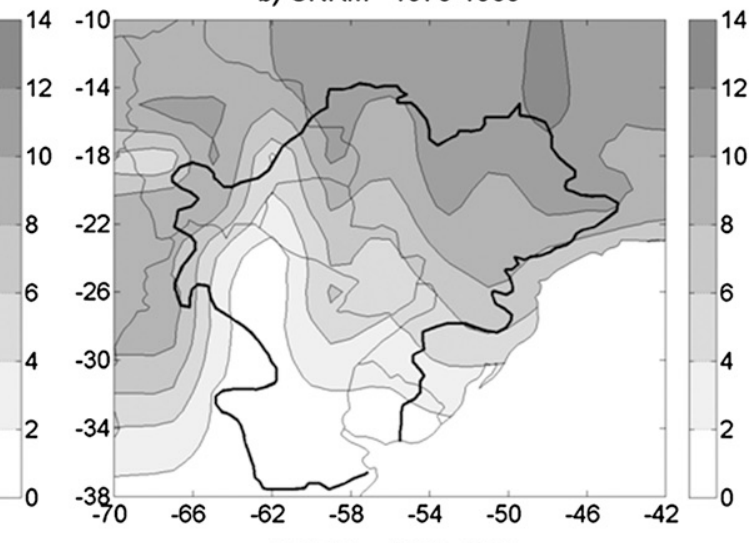

d) GFDL - 1973-1989
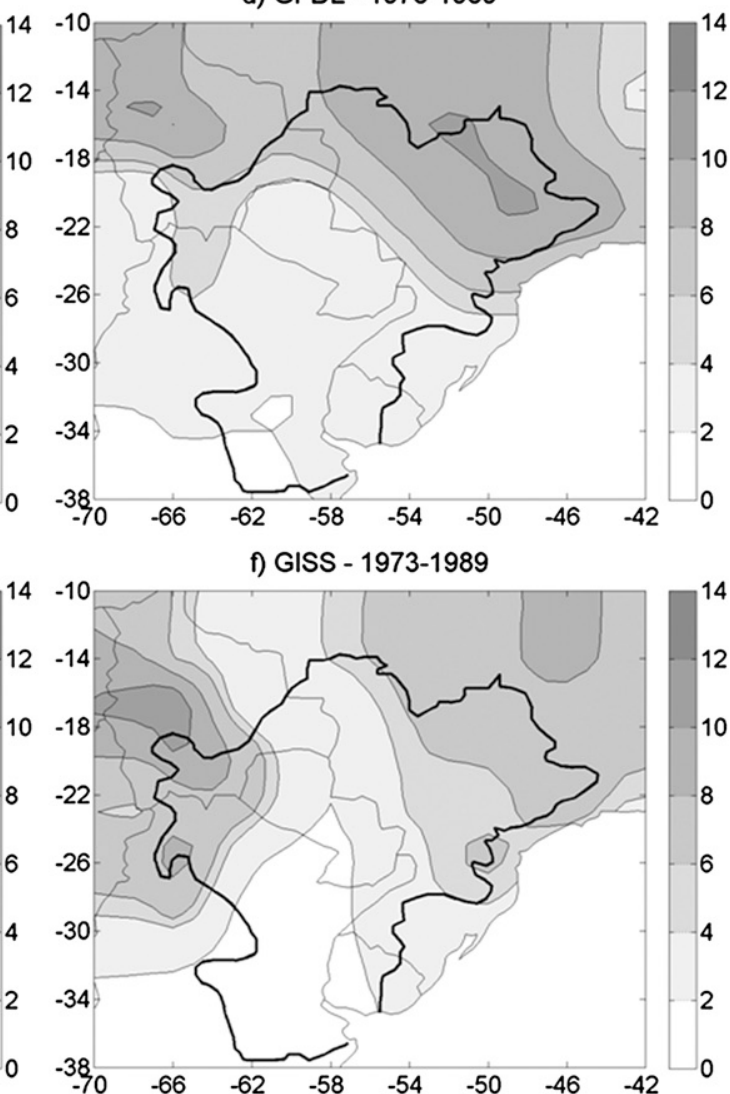

FIG. 6. Summer (DJF) mean precipitation $\left(\mathrm{mm} \mathrm{day}^{-1}\right)$ during the period $1973-89$ in (a) the observations, (b) CNRM, (c) ECHAM5, (d) GFDL2.0, (e) CGCM, and (f) GISS.

in the northern part of LPB, as summer rainfall amounts there are very similar to the observations, but GISS is drier than what is observed.

The ECHAM5 and CGCM annual rainfall estimates (Figs. 5c and 5e) appear to be the most accurate among the five GCMs. In fact, over the southern, east-central, and northern parts of the basin the difference between the observed and ECHAM5 precipitation amounts does not exceed $500 \mathrm{~mm} \mathrm{yr}^{-1}$ and the GISS error is smaller than $700 \mathrm{~mm} \mathrm{yr}^{-1}$ (which are large errors anyway). There is however a somewhat drier pattern over northern Argentina and southern Brazil (the upper and middle Paraguay and Paraná basins), but annual precipitation over the Uruguay basin is well represented, particularly in ECHAM5. This is due to the ability of ECHAM5 to capture the winter rainfall maximum over the UUR region (Fig. 7c). 
a) OBS - 1973-1989

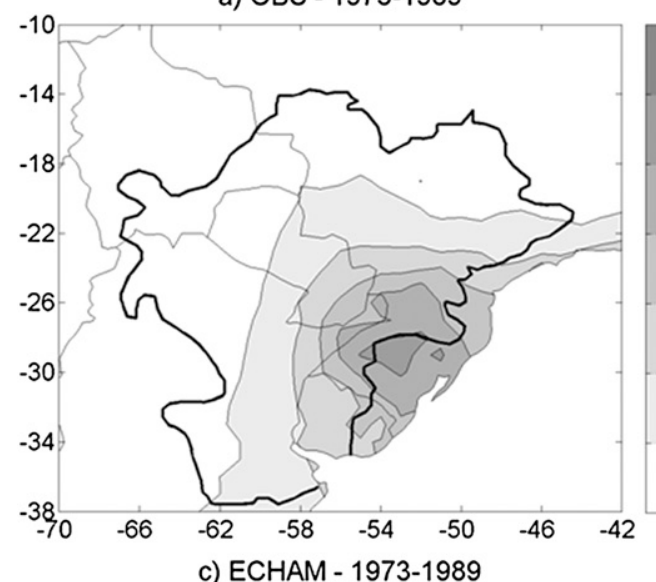

c) ECHAM - 1973-1989

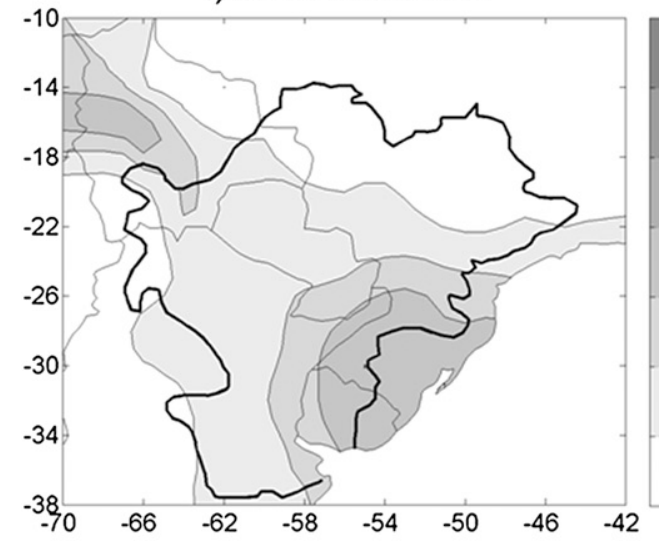

e) CGCM - 1973-1989

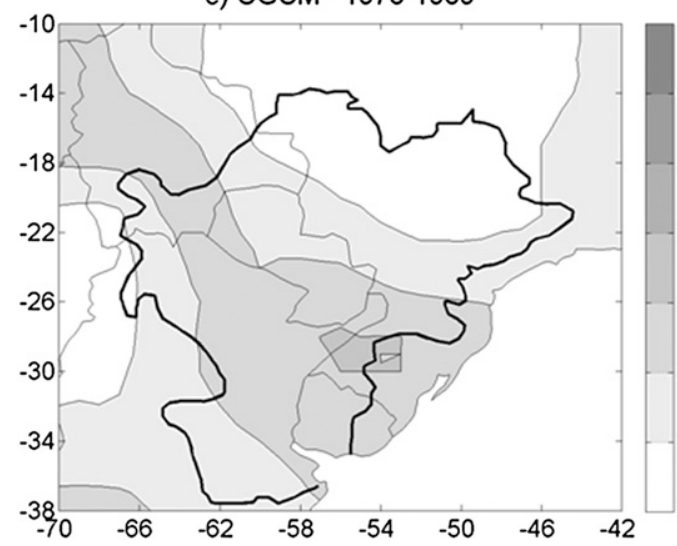

b) CNRM - 1973-1989

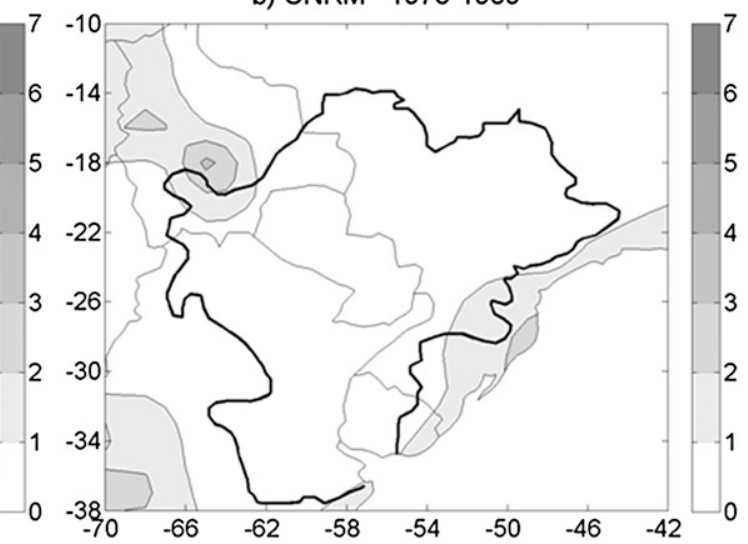

d) GFDL - 1973-1989

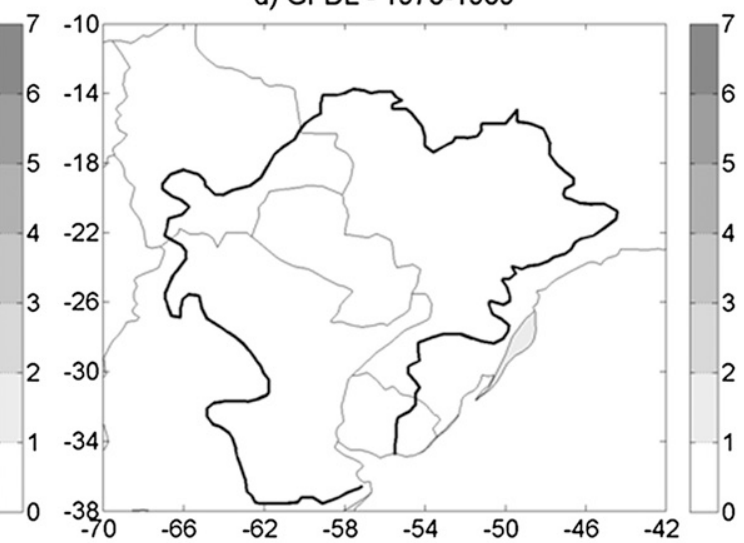

f) GISS - 1973-1989

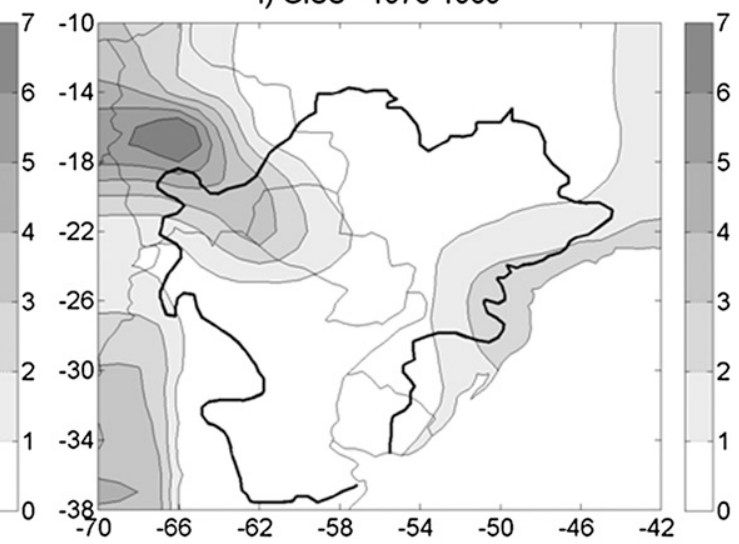

FIG. 7. As in Fig. 6, but for winter (JJA).

\section{VIC simulations of the LPB hydrological cycle}

The hydrological cycle of LPB is variable among the different subbasins. The Paraguay and the Paraná rivers are subject to a rainy season covering roughly from November to April and dry conditions during the rest of the year. However, streamflow response varies between the two rivers as the Paraguay basin has an extremely small slope (of about $0.05 \mathrm{~m} \mathrm{~km}^{-1}$ ) and the existence of the Pantanal region. These two facts explain the large lag between precipitation and streamflow maximums at the basin outlet (Camilloni and Barros 2000). The Paraná basin has a more pronounced slope, determining a streamflow maximum in summer and a minimum in winter, very similar to the precipitation cycle. The Uruguay streamflow displays a quick response to precipitation, although rainfall there does not have a marked seasonality and, thus, the annual hydrograph is relatively irregular. Results 
from VIC simulations using the observations are summarized in Fig. 8, which shows the hydrograph and the annual cycle of precipitation and temperature for each subbasin, at each closing point, and Table 1, which displays the skill parameters obtained from the simulations.

\section{a. Paraná River simulations}

Figure 8a shows the observed hydrograph at Jupiá and the resulting hydrograph obtained after calibration of VIC. The basin-mean accumulated rainfall and temperature are also shown. The streamflow regime is characterized by a flood season in summer, associated with convective activity in the SACZ region, and dry conditions in winter, with a streamflow minimum in August, which is consistent with the precipitation variability, characterized by a marked monsoonal pattern. Temperatures display highest values in the DJF season followed by cooler conditions in winter. At Posadas (Fig. 8b), the pattern is similar, but the presence of water reservoirs upstream of this location (including Itaipú in Brazil), for which VIC cannot account, leads to a worse fit. This is consistent with the skill parameters: the Jupiá simulation has NSE values above 0.5 and correlation coefficients about $0.9\left(R^{2}=0.81\right)$, while the Posadas NSE values are below 0 and the correlation coefficient is lower (Table 1). The precipitation and temperature variabilities in Posadas are very similar to those of Jupiá.

\section{b. Iguazú River}

The Iguazú River variability (Fig. 8c) is different from that of the Paraná, since precipitation there is present all year long and its changes in streamflow are controlled basically by changes in the mean temperature (see the temperature and precipitation annual cycles in Fig. 8c). Therefore, the annual hydrograph is quite homogeneous, without significant peaks and with a maximum during the cold season when the temperature (and, thus, evaporation) is at its minimum. VIC is also successful at simulating this river streamflow at Salto Caxias, with a small underestimation in winter and spring. However, statistical parameters show the calibration is satisfactory, with the correlation coefficient surpassing 0.9 and NSE values of 0.7 (Table 1).

\section{c. Paraguay River}

The Paraguay River basin is somewhat problematic for VIC. The observed streamflow at Ladario presents a minimum near the start of the rainy season, in NovemberDecember, and a maximum in May. This maximum results from a combination of spring/summer precipitation and the very small and uniform slope of the basin. After calibration, VIC is able to reproduce the timing of the annual maximum in May and the minimum near NovemberDecember (Fig. 8d). However, the magnitudes of both the minimum and the maximum are not properly handled (with an overestimated maximum and an underestimated minimum) and, thus, the statistical parameters do not show a good fit with the observed streamflow at Ladario: NSE acquires negative values, the bias is largest among all the closing points, and the correlation coefficient is about 0.3 (Table 1 ). The annual mean streamflow is $1442 \mathrm{~m}^{3} \mathrm{~s}^{-1}$ in the observations versus $2051 \mathrm{~m}^{3} \mathrm{~s}^{-1}$ in the simulations. These errors are in part due to the very few precipitation stations in that basin (see Fig. 2), and in part due to problems that VIC has with handling slow-water rivers. This could be solved in part by using the newest version of VIC, which includes the possibility of model watersheds that display lakes in a more accurate way by using a lake parameter file. This was not included in the simulations leading to these results (so analysis of this basin must be undertaken with care).

\section{d. Uruguay River}

The Uruguay River annual hydrograph is distinctive: streamflow results, as in the case of the Iguazú, from a compromise between rainfall (which is present all year long) and temperature, which has a clear peak in summer and a minimum in the cold season, mainly from June to August (Figs. 8e and 8f). VIC is very good at simulating the hydrograph at both closing points of this basin, with very high values of the two principal statistical parameters: NSE $=0.93$ and $R^{2}=0.95$ at Paso de los Libres and NSE $=0.92$ and $R^{2}=0.95$ at Salto Grande (Table 1$)$. The streamflow annual range is small, about $2500 \mathrm{~m}^{3} \mathrm{~s}^{-1}$.

\section{VIC simulations with biased and unbiased GCM data}

VIC forced with uncorrected GCM outputs of temperatures and precipitation leads to streamflows that differ markedly from the observations. Figure 9 shows the simulation results for the Paraná River at Jupiá (top panel) along with the temperature and precipitation climatology for each of the five GCMs. In terms of streamflow, CNRM and GFDL2.0 display large overestimations of the warm season maximum, with GFDL2.0 having a maximum about 3 times that of the observations $\left(28863 \mathrm{~m}^{3} \mathrm{~s}^{-1}\right.$ in this model versus $11238 \mathrm{~m}^{3} \mathrm{~s}^{-1}$ in the observations in February). ECHAM5, CGCM, and GISS, on the other hand, tend to slightly underestimate this maximum, by about a $20 \%-30 \%$. In winter all the models can accurately simulate the minimum in water availability. Summer differences are explained by the patterns of temperature and precipitation behavior in each model: CNRM and 
a) Paraná at Jupiá - Streamflow
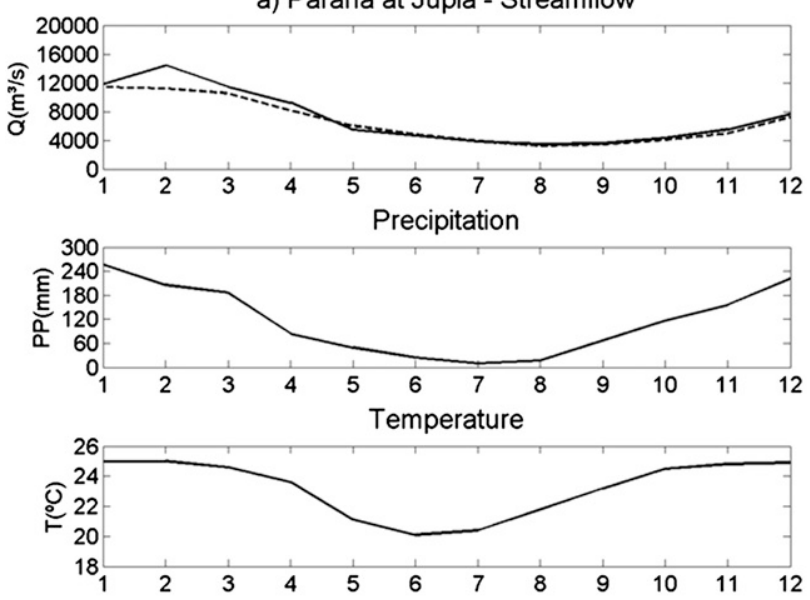

c) Iguazú at Salto Caxias - Streamflow
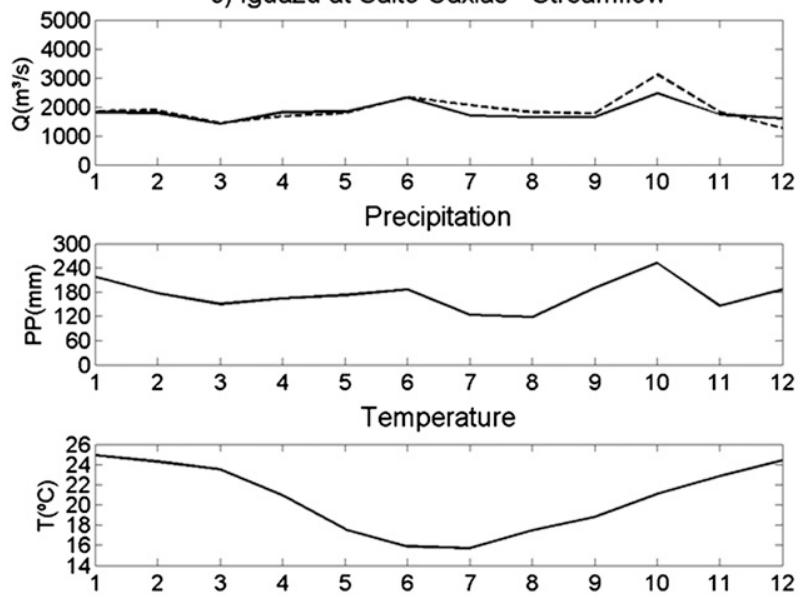

e) Uruguay at Paso de los Libres - Streamflow
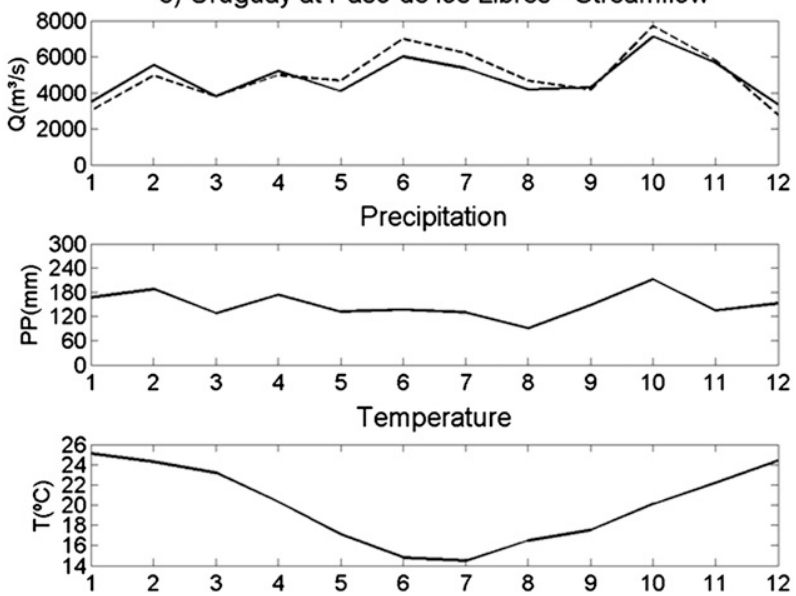

b) Paraná at Posadas - Streamflow
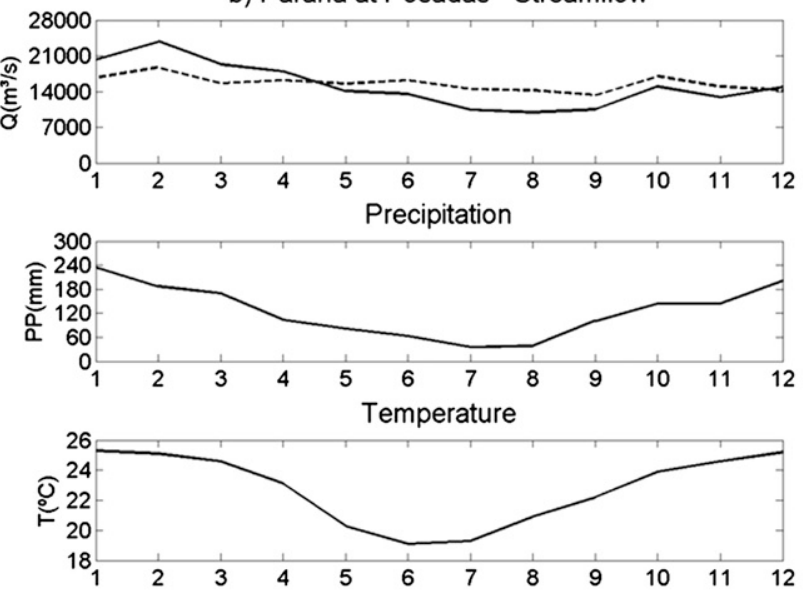

d) Paraguay at Ladario - Streamflow
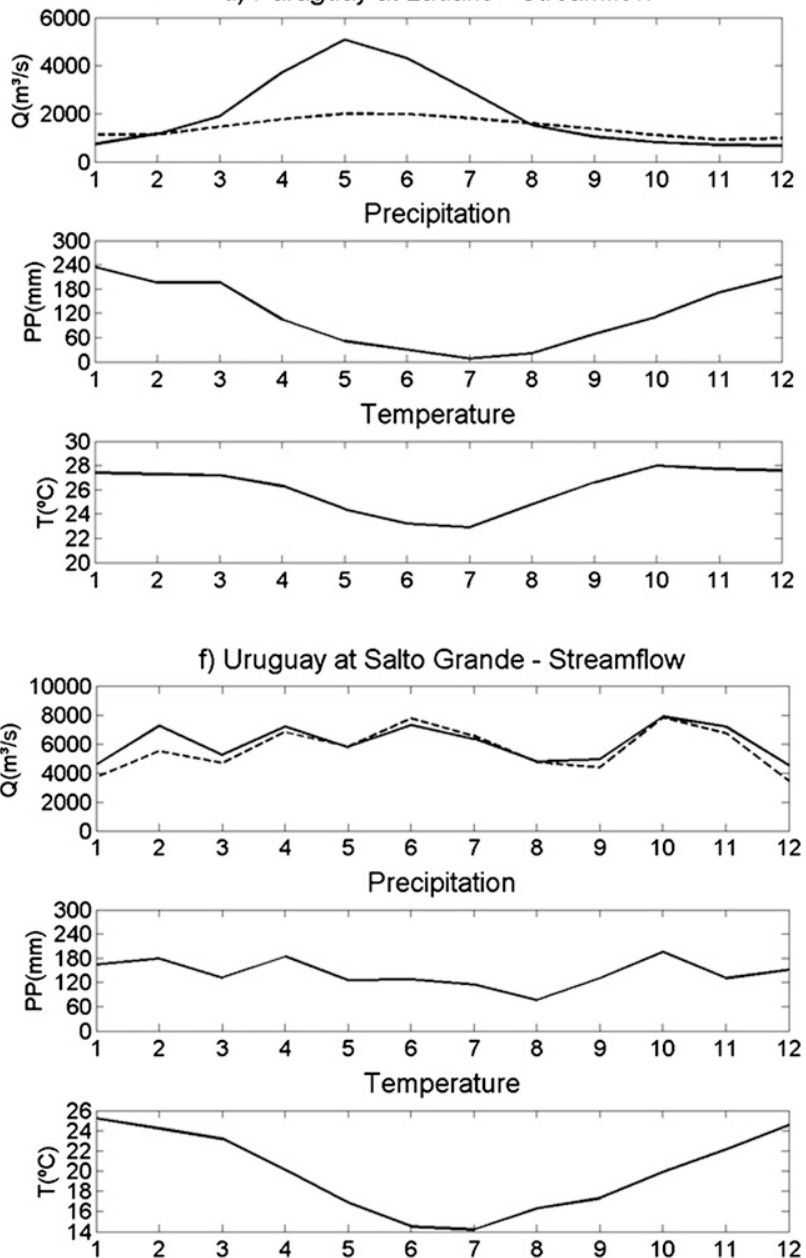

FIG. 8. The hydrological cycle at the selected closing points computed from the observed streamflows (dashed line) and derived from VIC simulations using observed precipitation and temperature data (solid line) at the (a) Paraná River at Jupiá, (b) Paraná River at Posadas, (c) Iguazú River at Salto Caxias, (d) Paraguay River at Ladario, (e) Uruguay River at Paso de los Libres, and (f) Uruguay River at Salto Grande. At each closing point, the annual cycles of the basin-mean precipitation and temperature are also shown. Units of the streamflows are $\mathrm{m}^{3} \mathrm{~s}^{-1}$, temperatures are ${ }^{\circ} \mathrm{C}$, and precipitation is $\mathrm{mm} \mathrm{yr}^{-1}$. 
TABLE 1. Calibration statistic parameters (NSE, bias, and $R^{2}$ ) for the VIC simulations using observations at the six selected closing points.

\begin{tabular}{lccrr}
\hline \hline & $Q^{\text {OBS }}\left(\mathrm{m}^{3} \mathrm{~s}^{-1}\right)$ & $Q^{\mathrm{SIM}}\left(\mathrm{m}^{3} \mathrm{~s}^{-1}\right)$ & NSE & Bias \\
\hline Jupiá & 6614 & 7161 & 0.5634 & 7.9568 \\
Posadas & 15598 & 15202 & $<0$ & -1.4761 \\
Salto Caxias & 1912 & 1825 & 0.7082 & -4.5589 \\
Ladario & 1442 & 2051 & $<0$ & 42.5333 \\
Paso de los Libres & 4972 & 4840 & 0.9302 & 0.4633 \\
Salto Grande & 5692 & 6114 & 0.9240 & -2.7006 \\
\hline
\end{tabular}

GFDL2.0 both have basin-mean precipitation results of about $250-300 \mathrm{~mm}$ in January and February, exceeding the observed precipitation in this basin (Fig. 8a). The other three GCMs simulate less precipitation, thus leading to less streamflow. This is consistent with the fact that CNRM and GFDL2.0 overestimate the warm season precipitation maximum (Figs. 5b, $6 \mathrm{~b}$ and $5 \mathrm{~d}, 6 \mathrm{~d}$ ) while ECHAM5, CGCM, and GISS, due to problems with resolving the ICTZ-related convection, underestimate it (Figs. 5c, 6c; 5e, 6e; and 5f, 6f). At Salto Caxias, in the Iguazú River (Fig. 10), CNRM, GFDL2.0, CGCM, and GISS simulate a water cycle similar to Jupiá's: a streamflow maximum in summer and a minimum in winter, which is not consistent with the observations. ECHAM5 is somewhat more realistic, properly handling the irregular behavior of the hydrograph, with no clear seasonal variations. The same difference pattern is visible in the case of the Uruguay River at Paso de los Libres (Fig. 12), with CNRM, GFDL2.0, CGCM, and GISS once again simulating a monsoonal-like hydrograph with maximums in summer and minimums in winter, and ECHAM5 being more accurate but with an all-year-long underestimation of the streamflow. These differences can be explained through the representation of seasonal precipitation in the GCMs: the first four GCMs are extremely dry in these two basins during the winter (Figs. 10 and 12), while ECHAM5 is able to simulate precipitation more precisely, which was already attributed to the good representation of the winter precipitation maximum in the UUR region (Fig. 7c). In the Paraguay River at Ladario (Fig. 11), all of the GCMs have problems representing the annual cycle of the streamflow, but a parts of these errors are due to the poor performance of VIC in that area. Future comparisons should be performed taking that into account. CNRM tends to represent excessive summer precipitation, which leads to an autumn maximum in streamflow that is higher than in actuality. GFDL2.0 and GISS, on the other hand, are extremely dry all year long, with underestimated streamflows. ECHAM5 and CGCM are in the middle of the other GCMs. It is interesting to note that all of the GCMs simulate well the very dry conditions in this region from April to October, with very low precipitation totals, so the main determining factor in how each model simulates the hydrological cycle of this basin is the ability to simulate the summer rainfall maximum.

The magnitudes of the bias for the simulations are displayed in Table 2 . Nearly all the simulations performed with native (biased) GCMs tend to have large bias values, with the largest values found generally in the simulations of the Paraguay River at Ladario (with a bias maximum of 240 in the simulation forced with CNRM data).

When the first unbiasing scheme is applied, the water cycle obtained with the GCMs becomes qualitatively much more similar to that simulated with the observations. Figure 13 shows the hydrographs for four selected closing points after the first unbiasing. It is clear that those models that displayed a systematic bias in either temperature or precipitation (e.g., CNRM and GFDL2.0, which simulated much less winter precipitation in UUR

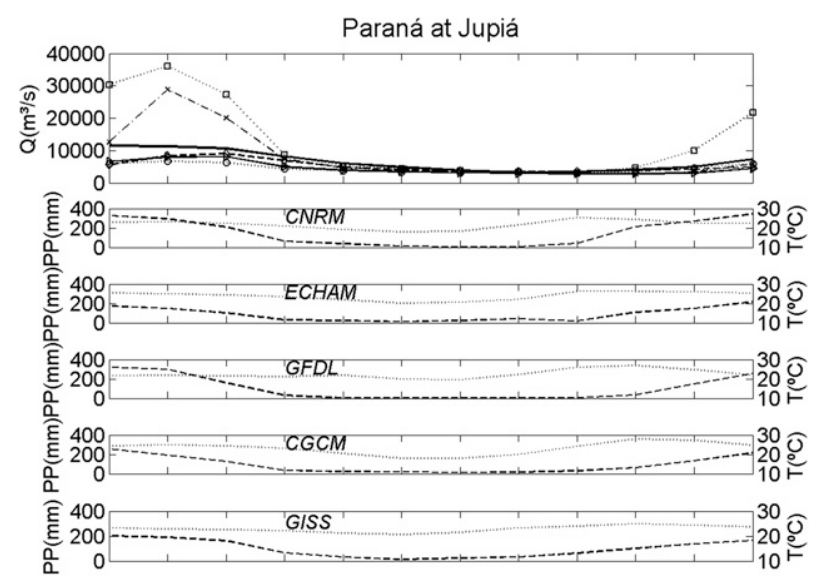

FIG. 9. (top) VIC model simulations forced with the native, biased GCMs outputs, of the Paraná River streamflow at Jupiá: the observed hydrograph is represented by the dark solid line, the VIC simulation forced with CNRM data is indicated by the dotted line with squares, VIC forced with ECHAM5 is represented by the dotted line with circles, VIC forced with GFDL2.0 is shown as a dashed-dotted line with crosses, the VIC simulation performed with CGCM forcings is displayed with the thin solid line with rightward-pointing arrows, and VIC forced with GISS is shown as a dashed line with squares. The second through sixth panels show the annual cycle of the temperature (dotted line) and precipitation (dashed line) in this basin for each of the five GCMs. Units of streamflows are $\mathrm{m}^{3} \mathrm{~s}^{-1}$, temperatures are in ${ }^{\circ} \mathrm{C}$, and precipitation is in $\mathrm{mm}$ month $^{-1}$. 


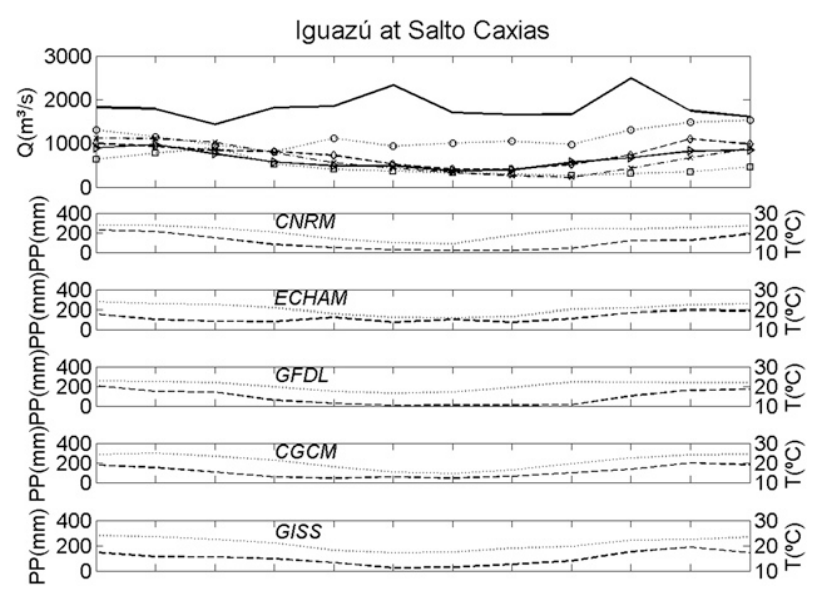

FIG. 10. As in Fig. 9, but for the Iguazú River at Salto Caxias.

and, thus, led to underestimations of the Uruguay River streamflow in JJA) perform better with this first scheme and these biases disappear. The Paraná River simulations at Jupiá (Fig. 13a), for example, now show more accurate DJF streamflows in CNRM and GFDL2.0 (which before the correction tended to overestimate them in this season), and roughly the same occurs in other cases, as in Paso de los Libres, in the Uruguay River basin (Fig. 13d). Consistently, the bias in almost all of the simulations is reduced (Table 3), with the only exceptions being Ladario and Salto Caxias in ECHAM5, Jupiá and Ladario in GFDL2.0, and Ladario in CGCM.

After applying the second unbiasing scheme, hydrograph simulations with the GCMs also become more accurate. Figure 14 shows the annual cycle of monthly mean streamflows at the same selected closing points as in Fig. 13: once again, it can be seen that the simulations are closer to the water cycle simulated with the observations, especially in the case of the Paraná River at Jupiá and the Uruguay River at Paso de los Libres. At

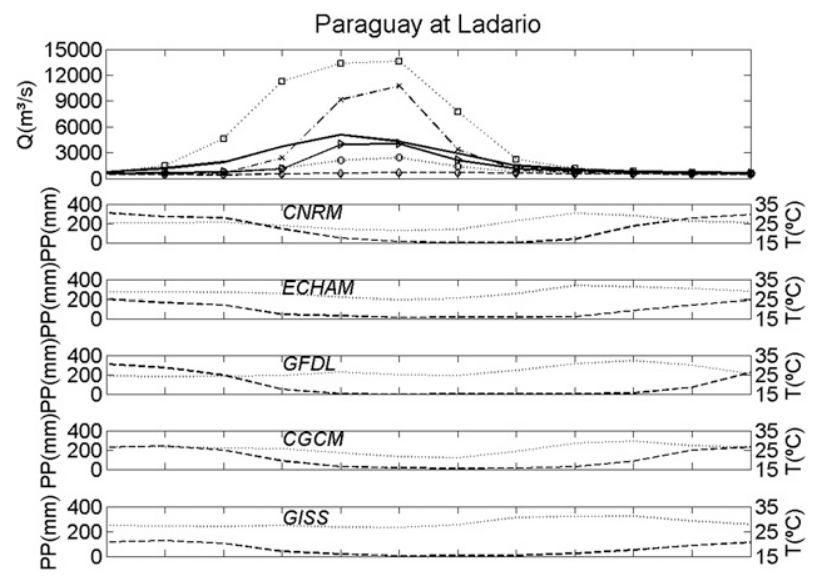

FIG. 11. As in Fig. 9, but for the Paraguay River at Ladario.

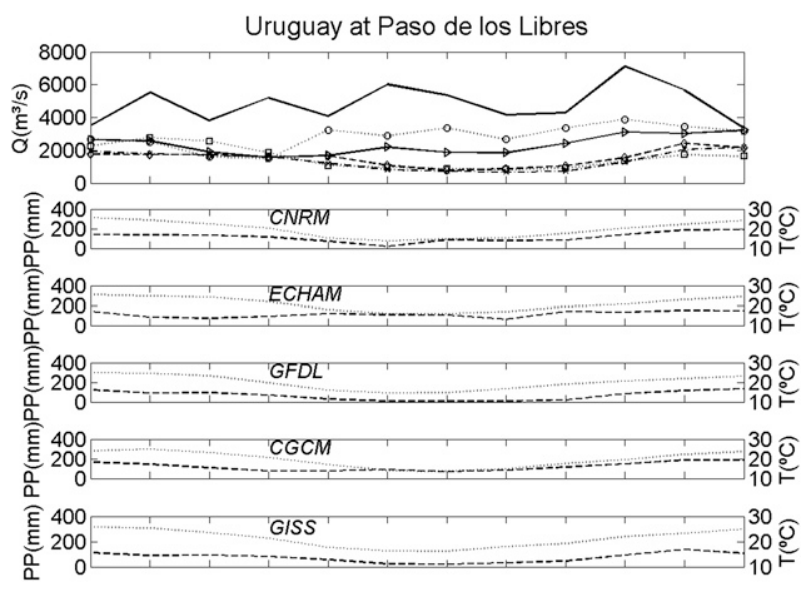

FIG. 12. As in Fig. 9, but for the Uruguay River at Paso de los Libres.

Salto Caxias the simulations also improve; nonetheless, all of the GCM simulations remain below that of the hydrograph obtained with the observation simulations. In terms of bias (Table 3), the results demonstrate that the simulations also become more accurate, with the exception of only a few cases.

It is worth mentioning that both unbiasing schemes improve the simulations of the annual mean streamflow. Month-to-month variability is in some cases improved but in some others it is not, so these schemes should not be considered for seasonal streamflow variation assessments, but only for examinations of annual means. Among the different closing points, Ladario is the one at which the unbiasing schemes proposed in this paper perform the worst. This suggests that the errors in the simulation of the hydrological cycle in that basin are not explained by the systematic errors in the atmospheric (temperature and precipitation) fields but have their origins in the problems of the physical representation of the watershed by the hydrological model.

\section{LPB future hydrology scenarios}

In spite of being forced under the same socioeconomic scenarios, GCMs tend to display quite different solutions from which to make inferences for the future climate.

TABLE 2. Bias computed from monthly VIC simulations using original (uncorrected) GCMs outputs.

\begin{tabular}{lrcrrr}
\hline & CNRM & ECHAM5 & GFDL2.0 & CGCM & GISS \\
\hline Jupiá & -99.8 & -31.9 & 24.1 & -32.2 & -21.8 \\
Salto Caxias & 75.6 & -40.7 & -66.0 & -65.8 & -60.8 \\
Posadas & -25.8 & -41.6 & -13.5 & -47.2 & -41.7 \\
Ladario & -239.7 & -29.8 & 74.2 & -3.1 & -61.9 \\
P. de los Libres & 68.5 & -42.5 & -72.0 & -53.5 & -69.5 \\
Salto Grande & 67.8 & -38.0 & -69.0 & -46.3 & -70.5 \\
\hline
\end{tabular}


a) Paraná at Jupiá

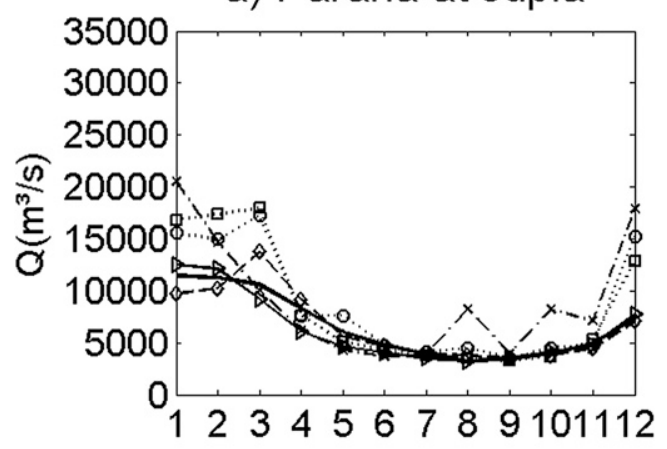

c) Paraguay at Ladario

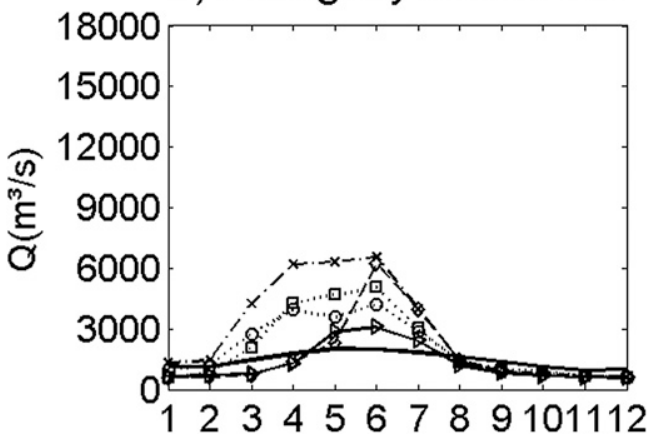

b) Iguazú at Salto Caxias

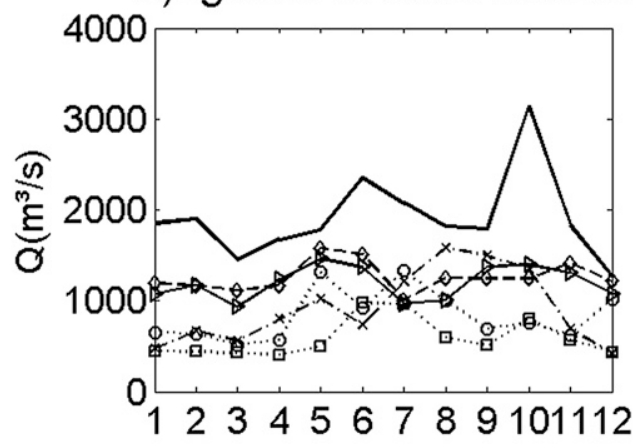

d) Uruguay at Paso de los Libres

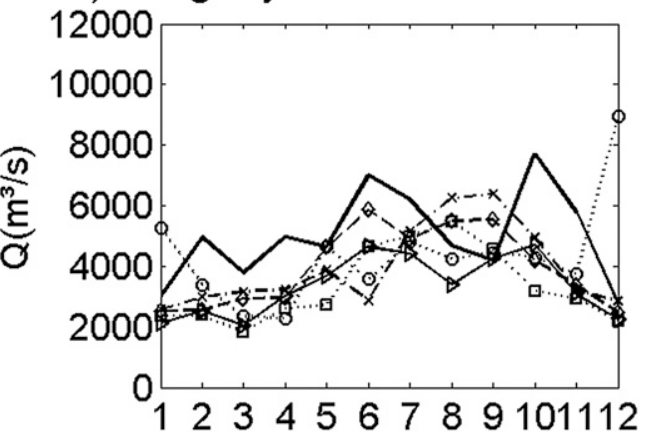

FIG. 13. VIC simulations results after application of the first unbiasing scheme to (a) the Paraná River at Jupiá, (b) the Iguazú River at Salto Caxias, (c) the Paraguay River at Ladario, and (d) the Uruguay River at Paso de los Libres. The observed hydrograph and that simulated by each GCM are represented the same way as in Figs. 9-12. Streamflow units are $\mathrm{m}^{3} \mathrm{~s}^{-1}$.

This fact can be explained by a number of factors: the different parameterization schemes, the differences in horizontal and vertical resolutions, problems in simulating low-frequency (mainly interdecadal) variability, etc. For this reason, it is usually difficult to find a consensus among the GCMs on to how some variables may behave in the future (precipitation is an example of this), while other variables are likely to have a determined pattern in the upcoming decades. Regardless of the scenario, all of the GCMs foresee an increase in the surface temperature for much of the world; however, in terms of precipitation the signal is not homogeneous and, while some models depict a moister panorama in some parts of the world for the near future, some others predict drier conditions in those same regions. LPB is not the exception, and the GCMs analyzed in this paper do not show a homogeneous rainfall pattern for the future.

Figure 15 shows the temperature variation for the 2030 and 2070 decades (with respect to the 1990 decade) in CNRM for two opposite scenarios: A2 and B1. It can be seen that the former scenario is more aggressive in terms of surface warming for both decades, with temperature increases of about $2^{\circ} \mathrm{C}$ for the 2030 decade and of about $3^{\circ}-4^{\circ} \mathrm{C}$ by 2070 . With some differences, all of the other

TABLE 3. The bias absolute values computed from the simulations with native, biased GCMs data (No-SCH) and after unbiasing with the application of the first scheme ( $\mathrm{SCH} 1)$ and the second scheme (SCH2). Values that improved after the application of SCH1 and SCH2 are displayed in boldface.

\begin{tabular}{|c|c|c|c|c|c|c|c|c|c|c|c|c|c|c|c|}
\hline & \multicolumn{3}{|c|}{ CNRM } & \multicolumn{3}{|c|}{ ECHAM5 } & \multicolumn{3}{|c|}{ GFDL2.0 } & \multicolumn{3}{|c|}{ CGCM } & \multicolumn{3}{|c|}{ GISS } \\
\hline & No-SCH & $\mathrm{SCH} 1$ & $\mathrm{SCH} 2$ & No-SCH & SCH1 & $\mathrm{SCH} 2$ & No-SCH & $\mathrm{SCH} 1$ & $\mathrm{SCH} 2$ & $\mathrm{No}-\mathrm{SCH}$ & $\mathrm{SCH} 1$ & $\mathrm{SCH} 2$ & No-SCH & SCH1 & $\mathrm{SCH} 2$ \\
\hline Jupiá & 99.8 & 27.9 & 69.8 & 31.9 & 31.5 & 21.0 & 24.1 & 36.9 & 9.3 & 32.2 & 6.2 & 2.7 & 21.8 & 0.4 & 27.3 \\
\hline Salto Caxias & 75.6 & 69.1 & 50.1 & 40.7 & 56.3 & 58.0 & 66.0 & 52.1 & 61.0 & 65.8 & 37.4 & 19.9 & 60.8 & 34.1 & 20.4 \\
\hline Posadas & 25.8 & 14.0 & 21.0 & 41.6 & $\mathbf{0 . 0}$ & 10.4 & 13.5 & 1.5 & 15.5 & 47.2 & 28.0 & 46.9 & 41.7 & 22.5 & 1.0 \\
\hline Ladario & 239.7 & 45.1 & 195.0 & 29.8 & 39.4 & 17.0 & 74.2 & 99.8 & 87.7 & 3.1 & 11.0 & 109.9 & 61.9 & 14.4 & 69.2 \\
\hline P. de los Libres & 68.5 & 33.2 & 11.0 & 42.5 & 12.8 & 29.0 & 72.0 & 20.4 & 39.0 & 53.5 & 33.1 & 3.9 & 69.5 & 20.9 & 2.2 \\
\hline Salto Grande & 67.8 & 26.4 & 7.3 & 38.0 & 0.1 & 24.6 & 69.0 & 14.1 & 34.2 & 46.3 & 29.2 & 14.7 & 70.5 & 9.7 & 3.9 \\
\hline
\end{tabular}


a) Paraná at Jupiá

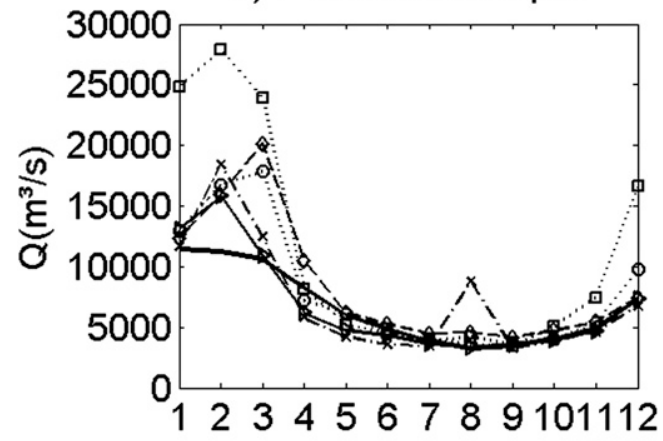

c) Paraguay at Ladario

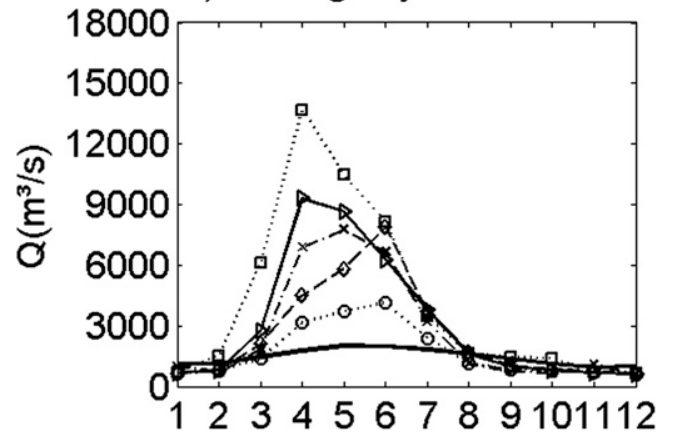

b) Iguazú at Salto Caxias

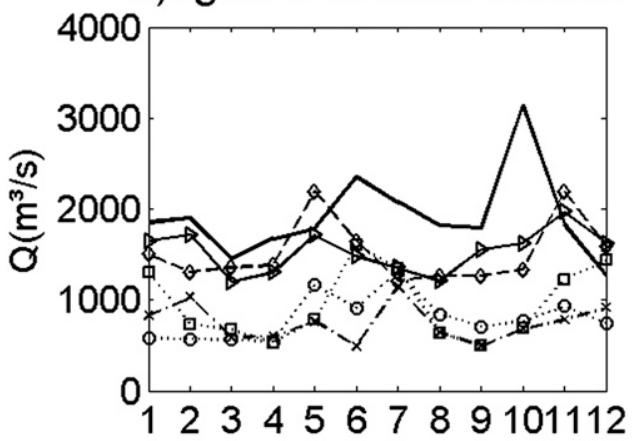

d) Uruguay at Paso de los Libres

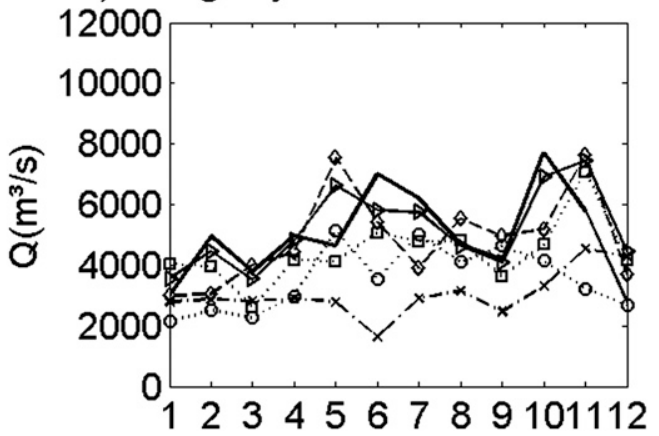

FIG. 14. As in Fig. 13, but after application of the second unbiasing scheme.

GCMs follow this pattern of a gradually warming planet, with varying rates and horizontal distribution, and this is why they are not shown. In the case of precipitation (Fig. 16), CNRM predicts a moister LPB in the A2 scenario for both future decades, with the only exceptions being a small area in the Upper Paraná basin by 2030 and in the far southern part of LPB by 2070 . On the other hand, the B1 scenario shows a less clear signal, with an alternating pattern of increased and decreased precipitation centers throughout the entire basin. This heterogeneous pattern is also repeated in the other GCMs: while some models predict an increase in rainfall for the future in certain areas, some others predict drier conditions, and so on (not shown). This adds a high degree of uncertainty to any inference one could make on the future of water availability for the LPB region.

When VIC was forced with future scenarios data, as was expected, different solutions were obtained for the different GCMs, the different decades, and the three scenarios: in some cases the streamflow increased, in some others it remained constant, and in others it decreased. As in all the scenarios and all the GCMs, there is a consensus that a warming pattern is expected for the upcoming decades over the whole basin; these differences among the solutions are directly linked to the differences in precipitation, which in some cases are forecasted to be large enough so as to offset the effects of the increase in evapotranspiration (due to the increased surface temperature) and, then, lead to an increase in the streamflows. This analysis was performed for the differences in the summer (DJF), winter (JJA), and annual streamflows with respect to their corresponding 1990-99 means.

In the case of the upper Paraná River at Jupiá (Table 4), there is a mixed signal for the future decades: in terms of the annual mean streamflow, some models (e.g., CGCM and GISS) predict a marked increase in both decades (2030 and 2070) under any of the emission scenarios, while other GCMs (e.g., CNRM, ECHAM5, and GFDL2.0) predict some relatively small increases or decreases in the streamflow depending on the scenario and the decade. All in all, these differences are in general no larger than $33 \%$. This nonhomogeneous pattern is also visible when analyzing the patterns of behavior of summer and winter streamflows for the future. CGCM and GISS are the GCMs that predict the largest differences with respect to the 1990 s, with a forecasted increase of about $150 \%$ by 2070 in CGCM under scenario A2. The mean obtained from directly averaging the different model outputs for each decade and each scenario predicts a gradual increase in streamflows, although in some cases this increase is supposed to be relatively continuous in time (e.g., under scenario A2, which by the 2030 s predicts an increase of about $20 \%$ and by the 2070 s an increase of about $30 \%$ ), and in some other cases there seems to be some changing 
a)

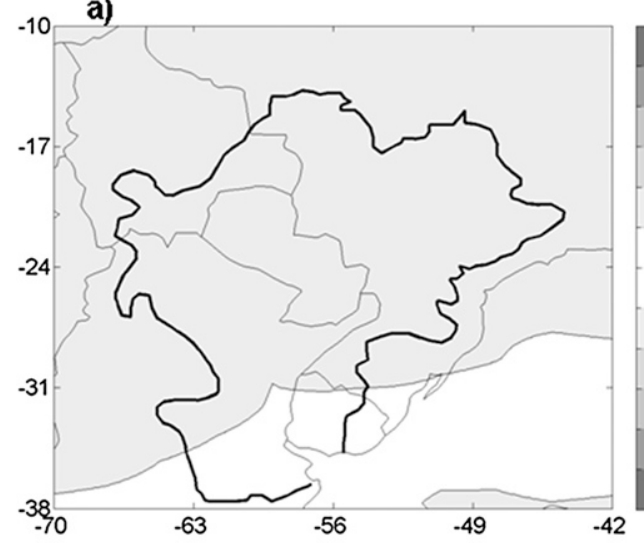

c)

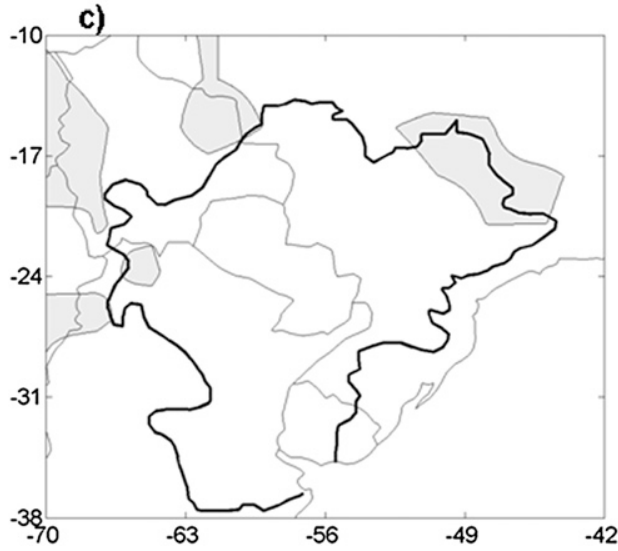

b)
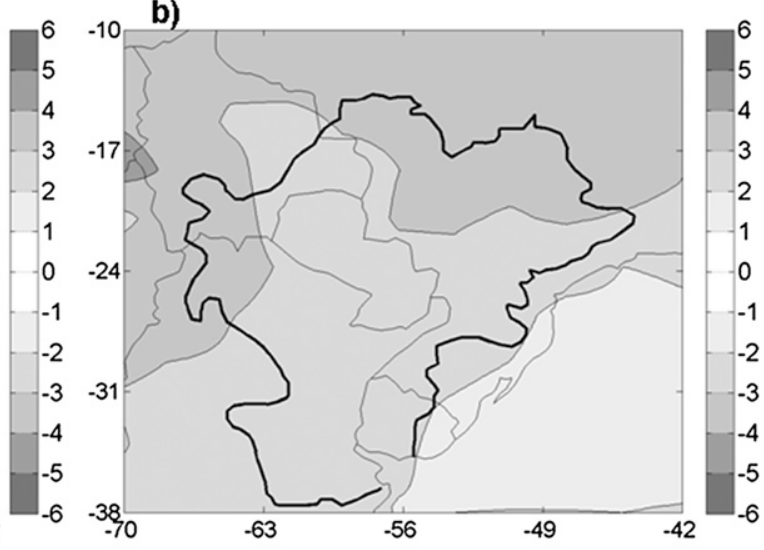

d)

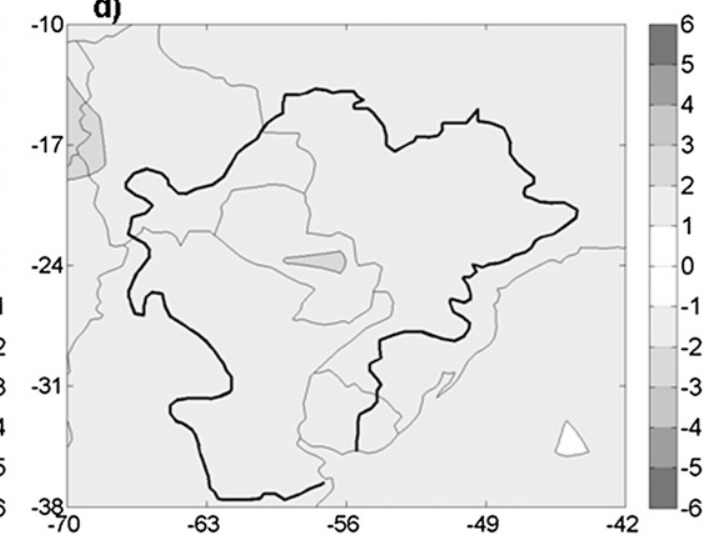

FIG. 15. Temperature variation $\left({ }^{\circ} \mathrm{C}\right)$ in CNRM for (a) the 2030 decade and the $\mathrm{A} 2$ scenario, (b) the 2070 decade and the A2 scenario, (c) the 2030 decade and the B1 scenario, and (d) the 2070 decade and the B1 scenario, with respect to the period 1990-99. Positive differences are contoured with solid lines.

trend, possibly linked to some kind of atmospheric lowfrequency variability (which GCMs are known to have problems reproducing).

The case of Salto Caxias (Table 5) is different from that of Jupiá: in this case all of the GCMs are unanimously predicting an increase in streamflow, for all the annual, summer, and winter means, with the only exception being GFDL2.0 in 2030 under scenario A1B, when a reduction of $14 \%$ is foreseen. The largest difference is predicted also by GFDL2.0 for 2070 under scenario A2, which forecasts an increase in summer streamflow of about $250 \%$. This model under the other scenarios also forecasts increases of around $200 \%$ for that time period.

For Ladario (Table 6), once again, the signals are mixed up, with some models forecasting large increases and some others decreases for the future decades. The mean of the GCMs predicts increases for the summer, winter, and annual mean streamflows. However, as was previously shown, VIC is very inaccurate in this basin and, in spite of having unbiased the data before performing these future climate simulations, the results there should be taken with even more care than the rest, as much of the expected trends in streamflows may be the result of the hydrology model problems themselves.

The case of the Uruguay River (Table 7) also shows some mixed signals among the GCMs and the emission scenarios. Some of the GCMs (e.g., CNRM and GFDL2.0) tend to suggest that increases would take place in the warm season, while the cold season would in turn experience a reduction in the mean. ECHAM5, in turn, predicts exactly the opposite.

In summary, GCMs foresee different precipitation scenarios for the upcoming decades and this has a large impact on the simulations of streamflows. In general, though, the means of the different simulations predict that annual streamflows will increase at all the closing points, under any of the three scenarios, and for both future decades. These increases would in general be about $10 \%-30 \%$. In Salto Caxias increases would be larger, but as this basin is the smallest among all the basins considered in the present work (with only 222 grid points), these results should be considered in that sense: small local changes would result in large variations of the streamflows there. 

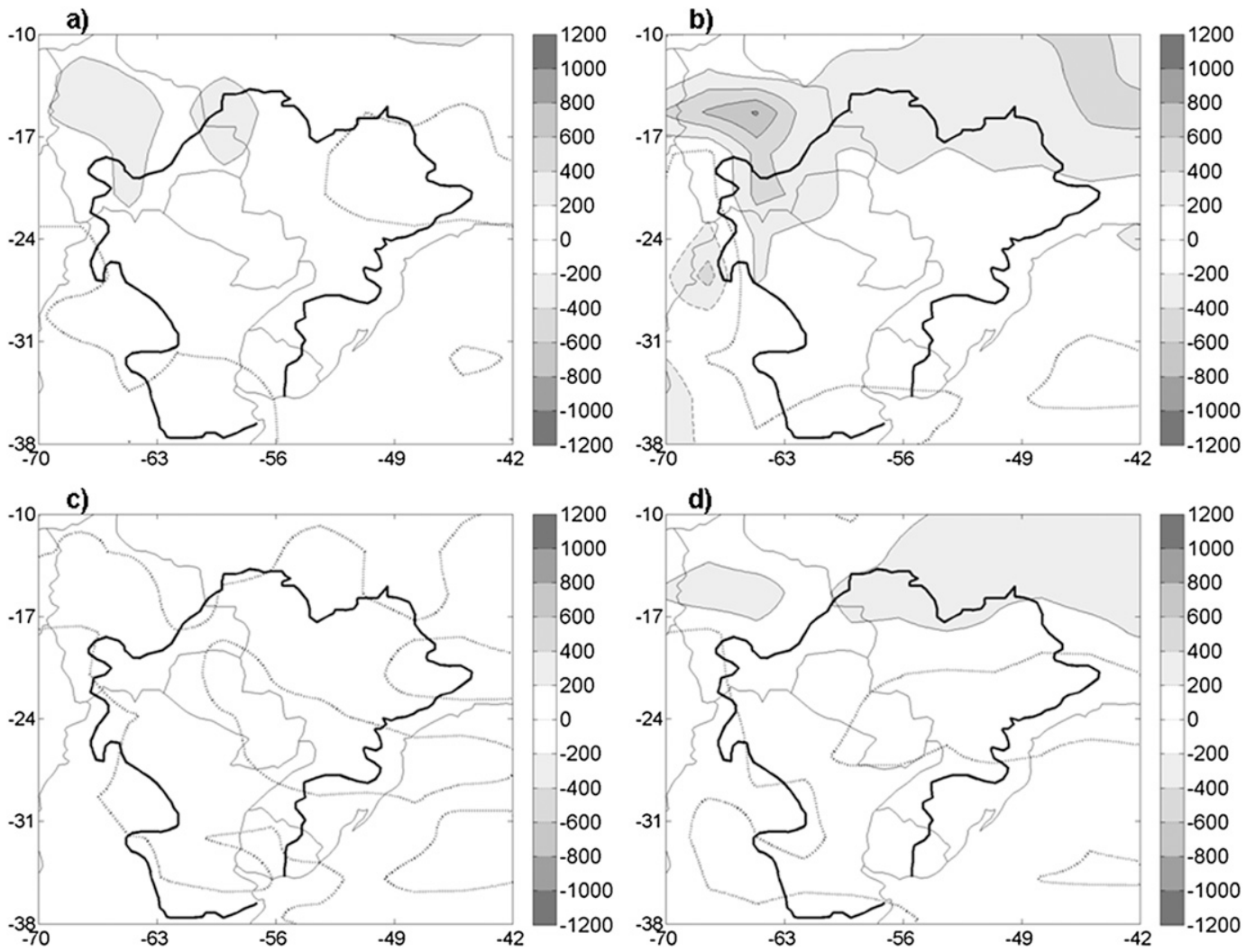

FIG. 16. As in Fig. 15, but for precipitation $\left(\mathrm{mm} \mathrm{yr}^{-1}\right)$. Negative differences (decreased precipitation in the future) are displayed as contours circled with dashed lines, and positive differences are shown with solid lines. The zero contour is indicated with a dotted line.

\section{Discussion and conclusions}

The results presented in this paper show that GCMs are not capable of reproducing the hydrological cycle of LPB adequately, resulting in the need for the application of corrective, unbiasing schemes on the meteorological fields. This lack of skill in representing the water cycle of LPB is a result of the climate models having several deficiencies in capturing the actual circulation patterns, which then leads to errors in both the temperature and precipitation fields. In particular in the case of the Paraná River basin, the principal error in the GCMs is the mishandling of the warm season rainfall activity in the SACZ region, with both CNRM and GFDL2.0 greatly overestimating the convective activity there, and ECHAM5 underestimating it. During the winter, ECHAM5 does properly represent the cold season precipitation maximum in southern Brazil, while the two other models are excessively dry in that area. Thus, CNRM and GFDL2.0 yield a great overestimation of the summer and autumn streamflow of the river, and they underestimate it during the winter. ECHAM5, meanwhile, is somewhat better in winter but it has several problems in summer, with huge underestimations.
Annual and seasonal mean temperatures in the GCMs are rather similar to the observations, so errors in the simulated streamflow of the Paraná River basin are mainly explained by errors in the precipitation fields. The case of the Iguazú River is rather similar to that of the Uruguay River basin with the main difference between the five GCMs simulations being explained by the skill in representing the winter precipitation in UUR (only ECHAM5 is capable of simulating it correctly). This suggests that simulations forced with ECHAM5 are the most realistic among the five GCMs. However, this model does not represent the actual magnitudes of the streamflow (it only represents it in a qualitative way) because, despite it proper handling of the cold season precipitation area, the amount of annual (and winter) rainfall is underestimated in the model, resulting in lower than actual streamflows. Neither CNRM nor GFDL2.0 capture the rainfall maximum in that region, and this leads to a very poor representation of the hydrological cycle in these two basins.

Finally, the case of the Paraguay River is characterized by an overestimated streamflow in summer in GFDL2.0 and underestimations in the two other models. The 
TABLE 4. Relative difference (\%) in the streamflow for future (2030 and 2070) decades with respect to the 1990-99 mean for scenarios A1B, A2, and B1, and for each of the five GCMs at Jupiá in the Paraná River. For each model and scenario, the top number corresponds to the variation in the summer (DJF) streamflow, the middle number to the variation in the winter (JJA), and the bottom number to the annual streamflow. The ensemble mean of the five models is displayed at the bottom of the table.

\begin{tabular}{|c|c|c|c|c|c|c|}
\hline & \multicolumn{3}{|c|}{2030} & \multicolumn{3}{|c|}{2070} \\
\hline & A1B & A2 & B1 & A1B & A2 & B1 \\
\hline \multirow[t]{3}{*}{ CNRM } & -29 & -26 & -37 & -25 & -5 & -25 \\
\hline & -4 & 1 & 1 & -5 & 3 & 5 \\
\hline & -9 & -4 & -14 & 0 & -2 & 10 \\
\hline \multirow[t]{3}{*}{ ЕСНАМ } & -10 & -10 & 3 & 0 & 17 & 6 \\
\hline & -14 & -9 & -4 & 9 & 16 & -12 \\
\hline & -4 & -8 & 1 & 5 & 20 & -3 \\
\hline \multirow[t]{3}{*}{ GFDL2.0 } & -58 & -21 & -6 & -46 & -44 & -48 \\
\hline & -35 & -25 & -21 & -33 & -9 & -26 \\
\hline & -24 & -3 & 14 & -33 & -12 & -27 \\
\hline \multirow[t]{3}{*}{ CGCM } & 22 & 55 & 8 & 20 & 156 & 55 \\
\hline & 30 & 73 & 15 & 14 & 66 & 15 \\
\hline & 35 & 99 & 14 & 21 & 114 & 30 \\
\hline \multirow[t]{3}{*}{ GISS } & 102 & - & 109 & 152 & - & 103 \\
\hline & 51 & - & 31 & 10 & - & 16 \\
\hline & 74 & - & 64 & 74 & - & 46 \\
\hline \multirow[t]{3}{*}{ Mean } & 6 & 0 & 15 & 20 & 31 & 18 \\
\hline & 6 & 10 & 4 & -1 & 19 & -1 \\
\hline & 14 & 21 & 16 & 13 & 30 & 11 \\
\hline
\end{tabular}

underestimation in ECHAM5 arises from the underestimation in precipitation that this model presents in summer across the upper Paraguay River. CNRM and GFDL2.0, on the other hand, yield rather similar precipitation patterns in the warm season in both locations for the maximums-minimums and in terms of amounts.

TABLE 5. As in Table 4, but at Salto Caxias in the Iguazú River.

\begin{tabular}{|c|c|c|c|c|c|c|}
\hline & \multicolumn{3}{|c|}{2030} & \multicolumn{3}{|c|}{2070} \\
\hline & A1B & A2 & B1 & A1B & $\mathrm{A} 2$ & B1 \\
\hline \multirow[t]{3}{*}{ CNRM } & 173 & 188 & 184 & 203 & 220 & 217 \\
\hline & 49 & 47 & 56 & 48 & 72 & 34 \\
\hline & 136 & 153 & 149 & 147 & 167 & 159 \\
\hline \multirow[t]{3}{*}{ ECHAM } & 49 & 87 & 71 & 61 & 74 & 52 \\
\hline & 17 & 77 & 35 & 46 & 118 & 37 \\
\hline & 45 & 91 & 69 & 66 & 125 & 65 \\
\hline \multirow[t]{3}{*}{ GFDL2.0 } & 201 & 211 & 151 & 196 & 246 & 176 \\
\hline & -14 & 0 & 3 & 40 & 11 & -16 \\
\hline & 74 & 75 & 64 & 90 & 111 & 62 \\
\hline \multirow[t]{3}{*}{ CGCM } & 45 & 41 & 23 & 29 & 48 & 15 \\
\hline & 74 & 104 & 27 & 35 & 95 & 33 \\
\hline & 41 & 55 & 21 & 27 & 60 & 16 \\
\hline \multirow[t]{3}{*}{ GISS } & 36 & - & 40 & 40 & - & 33 \\
\hline & 39 & - & 59 & 60 & - & 63 \\
\hline & 27 & - & 46 & 38 & - & 44 \\
\hline \multirow[t]{3}{*}{ Mean } & 101 & 132 & 94 & 106 & 147 & 99 \\
\hline & 32 & 57 & 36 & 46 & 74 & 30 \\
\hline & 65 & 94 & 70 & 74 & 116 & 69 \\
\hline
\end{tabular}

TABle 6. As in Table 4, but at Ladario in the Paraguay River.

\begin{tabular}{|c|c|c|c|c|c|c|}
\hline & \multicolumn{3}{|c|}{2030} & \multicolumn{3}{|c|}{2070} \\
\hline & A1B & A2 & B1 & A1B & $\mathrm{A} 2$ & B1 \\
\hline \multirow[t]{3}{*}{ CNRM } & 17 & 24 & -4 & 41 & 10 & 33 \\
\hline & -16 & 23 & 4 & 2 & 19 & 31 \\
\hline & -11 & 6 & -12 & 2 & -2 & 6 \\
\hline \multirow[t]{3}{*}{ ECHAM } & -26 & -24 & -30 & 63 & 6 & -23 \\
\hline & 49 & 76 & 41 & 29 & 76 & 78 \\
\hline & 10 & 24 & 8 & 39 & 46 & 32 \\
\hline \multirow[t]{3}{*}{ GFDL2.0 } & 111 & 8 & 67 & -40 & 35 & -20 \\
\hline & -39 & -18 & -31 & -56 & -59 & -16 \\
\hline & 0 & -6 & -1 & -45 & -21 & -25 \\
\hline \multirow[t]{3}{*}{ CGCM } & 20 & 13 & 0 & 24 & -2 & 10 \\
\hline & 142 & 221 & 150 & 191 & 178 & 125 \\
\hline & 88 & 110 & 49 & 111 & 124 & 82 \\
\hline \multirow[t]{3}{*}{ GISS } & 28 & - & 34 & 7 & - & 4 \\
\hline & 16 & - & 56 & 54 & - & 38 \\
\hline & 67 & - & 76 & 88 & - & 68 \\
\hline \multirow[t]{3}{*}{ Mean } & 30 & 5 & 13 & 19 & 12 & 1 \\
\hline & 30 & 75 & 44 & 44 & 53 & 51 \\
\hline & 31 & 33 & 24 & 39 & 37 & 33 \\
\hline
\end{tabular}

However, the simulated streamflows differ markedly. Although GCMs are a good tool for understanding the present climate and for inducing the potential variability of climate in the upcoming decades (due to both humanforced climate change and natural variability), they are still far from being realistic in many aspects, like representing the main regional features of precipitation across southern South America as well as low-frequency climate variability events like El Niño-La Niña (Raphael and Holland 2006; Vera and Silvestri 2009). Hence, unbiasing the meteorological fields becomes crucial.

TABLE 7. As in Table 4, but at Paso de los Libres in the Uruguay River.

\begin{tabular}{|c|c|c|c|c|c|c|}
\hline & \multicolumn{3}{|c|}{2030} & \multicolumn{3}{|c|}{2070} \\
\hline & A1B & $\mathrm{A} 2$ & B1 & A1B & $\mathrm{A} 2$ & B1 \\
\hline \multirow[t]{3}{*}{ CNRM } & 11 & 20 & 22 & 41 & 46 & 43 \\
\hline & -7 & -5 & 2 & -2 & 9 & -24 \\
\hline & 18 & 25 & 31 & 35 & 34 & 28 \\
\hline \multirow[t]{3}{*}{ ECHAM } & -58 & -52 & -54 & -54 & -51 & -53 \\
\hline & 55 & 31 & 18 & 58 & 88 & 13 \\
\hline & -2 & 7 & -1 & 5 & 37 & -2 \\
\hline \multirow[t]{3}{*}{ GFDL2.0 } & 60 & 40 & 16 & 70 & 91 & 70 \\
\hline & -41 & -27 & -34 & -7 & -45 & -27 \\
\hline & 19 & 19 & 14 & 36 & 25 & 26 \\
\hline \multirow[t]{3}{*}{ CGCM } & 47 & 35 & 29 & 32 & 40 & 12 \\
\hline & 0 & 84 & -12 & -21 & 61 & -15 \\
\hline & 34 & 68 & 26 & 28 & 58 & 22 \\
\hline \multirow[t]{3}{*}{ GISS } & 30 & - & 50 & 39 & - & 34 \\
\hline & -8 & - & 1 & -34 & - & 31 \\
\hline & 13 & - & 43 & 36 & - & 43 \\
\hline \multirow[t]{3}{*}{ Mean } & 18 & 11 & 13 & 26 & 31 & 21 \\
\hline & 0 & 21 & -5 & 12 & 28 & -4 \\
\hline & 16 & 30 & 23 & 28 & 39 & 23 \\
\hline
\end{tabular}


Two unbiasing schemes were applied in this paper, and both of them were shown to be useful in, at least partially, diminishing the errors in the GCMs. However, both schemes have some deficiencies: the first scheme corrects the temperature and precipitation data by the difference between the GCM and observed means in the period 1973-89 (because the information available at the time of writing did not include observed data before 1973). This implicitly assumes that this 17 -yr period is long enough to obtain confident mean values. However, this period could be somewhat short ( $\geq 30 \mathrm{yr}$ would be preferable), and this could influence the results. In the case of the second scheme, the percentiles of temperature and precipitation (for each GCM and for the observations) were also computed for the period 1973-89, and this could also lead to some deficiencies in the scheme. Notwithstanding, and in spite of the relatively short period in which the means and percentiles were computed, both schemes were shown to be good at unbiasing the precipitation and temperature data and, then, at improving the representation of the water cycle of the LPB region, especially in terms of the annual mean streamflow (for seasonal means, better options for unbiasing would be either using another statistical method or, instead, using dynamical downscaling methodologies). These schemes could also be helpful in unbiasing future climate scenarios from the same or others GCMs, as one of the main present interests in the climate and hydrology community is the prediction of water availability for the upcoming decades.

Future-scenario simulations show mixed signals in terms of predicted streamflows for the next few decades at the different subbasins. However, the mean of the simulations tends to suggest a gradual increase in streamflow in the future under any of the different emission scenarios, which would actually suggest that although temperatures would increase (and, then, evaporation would also become larger), the effects of varying (increasing) precipitation would lead to an increase in freshwater availability over the basin. These results should be taken with care, as GCMs are still far from being accurate at representing the actual climate and there is also a certain degree of uncertainty related to land use changes for the next few decades, which would determine very different streamflows from those simulated in this paper.

Acknowledgments. The research leading to these results was partially funded by the European Community's Seventh Framework Programme (FP7/2007-2013) under Grant Agreement 212492 (CLARIS LPB: A Europe-South America Network for Climate Change Assessment and Impact Studies in La Plata Basin) and by Grants ANPCYT PICT07-00400, CONICET PIP5400, and UBACYT-X033 to the University of Buenos Aires.
The author would like to acknowledge the Program for Climate Model Diagnosis and Intercomparison (PCMDI) for collecting and archiving the model data and Dr. Vicente Barros for his fruitful comments on this manuscript. The three anonymous reviewers' suggestions to improve this paper are also kindly appreciated.

\section{REFERENCES}

Barros, V. R., M. E. Castañeda, and M. E. Doyle, 2000: Recent precipitation trends in southern South America east of the Andes: An indication of climatic variability. Southern Hemisphere Paleo- and Neoclimates, P. P. Smolka and W. Volkheimer, Eds., Springer-Verlag, 187-206.

Berbery, E. H., and V. R. Barros, 2002: The hydrological cycle of the La Plata Basin in South America. J. Hydrometeor., 3, 630-645.

Berri, G. J., M. A. Ghietto, and N. O. García, 2002: The influence of ENSO in the flows of the upper Paraná River of South America over the past 100 years. J. Hydrometeor., 3, 57-65.

Camilloni, I. A., 2005: Extreme flood events in the Uruguay River of South America. VAMOS Newsletter, No. 2, International CLIVAR Project Office, Southampton, United Kingdom, 23-25.

, and V. R. Barros, 2000: The Paraná River response to El Niño 1982-83 and 1997-98 events. J. Hydrometeor., 1, 412-430.

— , and - 2003: Extreme discharge events in the Paraná River and their climate forcing. J. Hydrol., 278, 94-106.

Collischonn, W., R. Haas, I. Andreolli, and C. Tucci, 2005: Forecasting River Uruguay flow using rainfall forecasts from a regional weather-prediction model. J. Hydrol., 305, 87-98.

Dai, A., 2006: Precipitation characteristics in eighteen coupled climate models. J. Climate, 19, 4605-4630.

Delworth, T., and Coauthors, 2006: GFDL's CM2 global coupled climate models. Part I: Formulation and simulation characteristics. J. Climate, 19, 643-674.

Distributed Active Archive Center, 2000: Global Soil Data Products (IGBP-DIS). Oak Ridge National Laboratory Distributed Active Archive Center, CD-ROM. [Available online at http://daac.ornl.gov/SOILS/guides/igbp.html.]

Doyle, M. E., R. I. Saurral, and V. R. Barros, 2008: Drought conditions in northeastern Argentina. Preprints, $X V$ Brazilian Congress of Meteorology, Sao Paulo, Brazil, Sociedade Brasileira de Meteorología, 1-5.

Flato, G. M., cited 2009: The Third Generation Coupled Global Climate Model (CGCM3). [Available online at http://www. ec.gc.ca/ccmac-cccma/default.asp?lang $=$ En\&n=1299529F-1.]

García, N., and W. M. Vargas, 1998: The temporal climatic variability in the 'Río de la Plata' basin displayed by the river discharges. Climatic Change, 38, 359-379.

Grimm, A. M., and R. G. Tedeschi, 2009: ENSO and extreme rainfall events in South America. J. Climate, 22, 1589-1609.

— , V. R. Barros, and M. E. Doyle, 2000: Climate variability in southern South America associated with El Niño and La Niña events. J. Climate, 13, 35-58.

Hansen, M. C., R. S. DeFries, J. R. G. Townshend, and R. Sohlberg, 2000: Global land cover classification at $1 \mathrm{~km}$ resolution using a classification tree approach. Int. J. Remote Sens., 21, 1331-1364.

Laing, A. G., 2004: Cases of heavy precipitation and flash floods in the Caribbean during El Niño winters. J. Hydrometeor., 5, 577-594.

Liang, X., D. P. Lettenmaier, E. F. Wood, and S. J. Burges, 1994: A simple hydrologically based model of land surface water and 
energy fluxes for GSMs. J. Geophys. Res., 99 (D7), 14 41514428 .

$\_, \ldots$, and — $ـ$ 1996: One-dimensional statistical dynamic representation of subgrid spatial variability of precipitation in the two-layer Variable Infiltration Capacity model. J. Geophys. Res., 101 (D16), 21 403-21 422.

Lohmann, D., R. Nolte-Holube, and E. Raschke, 1996: A largescale horizontal routing model to be coupled to land surface parameterization schemes. Tellus, 48A, 708-721.

— E. Raschke, B. Nijssen, and D. P. Lettenmaier, 1998: Regional scale hydrology: 1. Formulation of the VIC-2L model coupled to a routing scheme. Hydrol. Sci. J., 43, 131-141.

Mattheussen, B., R. L. Kirschbaum, I. A. Goodman, G. M. O'Donnell, and D. P. Lettenmaier, 2000: Effects of land cover change on streamflow in the interior Columbia River basin (USA and Canada). Hydrol. Processes, 14, 867-885.

Mo, K. C., J. Nogues-Paegle, and R. Wayne Higgins, 1997: Atmospheric processes associated with summer floods and droughts in the central United States. J. Climate, 10, 3028-3046.

Nijssen, B. N., D. P. Lettenmaier, X. Liang, S. W. Wetzel, and E. F. Wood, 1997: Streamflow simulation for continental-scale river basins. Water Resour. Res., 33, 711-724.

Nogués-Paegle, J., and K. C. Mo, 1997: Alternating wet and dry conditions over South America during summer. Mon. Wea. Rev., 125, 279-291.

Penalba, O. C., and W. M. Vargas, 2008: Variability of low monthly rainfall in La Plata Basin. Meteor. Appl., 15, 313-323.

Perkins, S. E., A. J. Pitman, N. J. Holbrook, and J. McAneney, 2007: Evaluation of the AR4 climate models' simulated daily maximum temperature, minimum temperature, and precipitation over Australia using probability density functions. J. Climate, 20, 4356-4376.

Pielke, R. A., and M. W. Downton, 2000: Precipitation and damaging floods: Trends in the United States, 1932-97. J. Climate, 13, 3625-3637.

Raphael, M., and M. Holland, 2006: Twentieth century simulation of the Southern Hemisphere climate in coupled models. Part I: Large scale circulation variability. Climate Dyn., 26, 217-228, doi:10.1007/s00382-005-0082.
Roeckner, E., and Coauthors, 2006: Sensitivity of simulated climate to horizontal and vertical resolution in the ECHAM5 atmosphere model. J. Climate, 19, 3771-3791.

Russell, G. L., cited 2009: 4x3 atmosphere-ocean model documentation. [Available online at http://aom.giss.nasa.gov/doc4x3.html.]

Salas-Meliá, D., and Coauthors, 2005: Description and validation of the CNRM-CM3 global coupled model. CNRM Working Note 103, 36 pp.

Saurral, R. I., V. R. Barros, and D. P. Lettenmaier, 2008: Land use impact on the Uruguay River discharge. Geophys. Res. Lett., 35, L12401, doi:10.1029/2008GL033707.

Seguí, P. Q., E. Martin, F. Habets, and J. Noilhan, 2009: Improvement, calibration and validation of a distributed hydrological model over France. Hydrol. Earth Syst. Sci., 13, 163-181.

Solomon, S., D. Qin, M. Manning, M. Marquis, K. Averyt, M. M. B. Tignor, H. L. Miller Jr., and Z. Chen, Eds., 2007: Climate Change 2007: The Physical Science Basis. Cambridge University Press, 996 pp.

Su, F., and D. P. Lettenmaier, 2009: Estimation of surface water budget of La Plata Basin. J. Hydrometeor., 10, 981-998.

_ J. C. Adam, L. C. Bowling, and D. P. Lettenmaier, 2005: Streamflow simulations of the terrestrial Arctic domain. J. Geophys. Res., 110, D08112, doi:10.1029/2004JD005518.

_ _ Y. Hong, and D. P. Lettenmaier, 2008: Evaluation of TRMM Multisatellite Precipitation Analysis (TMPA) and its utility in hydrologic prediction in the La Plata Basin. J. Hydrometeor., 9, 622-640.

Vera, C. S., and G. Silvestri, 2009: Precipitation interannual variability in South America from the WCRP-CMIP3 multimodel dataset. Climate Dyn., 32, 1003-1014.

— , P. K. Vigliarolo, and E. H. Berbery, 2002: Cold season synoptic-scale waves over subtropical South America. Mon. Wea. Rev., 130, 684-699.

— , and Coauthors, 2006: Toward a unified view of the American monsoon systems. J. Climate, 19, 4977-5000.

Wood, A. W., E. P. Maurer, A. Kumar, and D. P. Lettenmaier, 2002: Long-range experimental hydrologic forecasting for the eastern United States. J. Geophys. Res., 107, 4429, doi:10.1029/ 2001JD000659. 